\title{
Use of pigs as a potential model for research into dietary modulation of the human gut microbiota
}

\author{
Sonja N. Heinritz, Rainer Mosenthin and Eva Weiss* \\ Institute of Animal Nutrition, University of Hohenheim, 70593 Stuttgart, Germany
}

\section{Abstract}

The human intestinal microbial ecosystem plays an important role in maintaining health. A multitude of diseases including diarrhoea, gastrointestinal inflammatory disorders, such as necrotising enterocolitis (NEC) of neonates, and obesity are linked to microbial composition and metabolic activity. Therefore, research on possible dietary strategies influencing microbial composition and activity, both preventive and curative, is being accomplished. Interest has focused on pre- and probiotics that stimulate the intestinal production of beneficial bacterial metabolites such as butyrate, and beneficially affect microbial composition. The suitability of an animal model to study dietary linked diseases is of much concern. The physiological similarity between humans and pigs in terms of digestive and associated metabolic processes places the pig in a superior position over other non-primate models. Furthermore, the pig is a human-sized omnivorous animal with comparable nutritional requirements, and shows similarities to the human intestinal microbial ecosystem. Also, the pig has been used as a model to assess microbiota-health interactions, since pigs exhibit similar syndromes to humans, such as NEC and partly weanling diarrhoea. In contrast, when using rodent models to study diet-microbiota-health interactions, differences between rodents and humans have to be considered. For example, studies with mice and human subjects assessing possible relationships between the composition and metabolic activity of the gut microbiota and the development of obesity have shown inconsistencies in results between studies. The present review displays the similarities and differences in intestinal microbial ecology between humans and pigs, scrutinising the pig as a potential animal model, with regard to possible health effects.

Key words: Intestinal microbiota: Humans: Pig model: Nutrition

\section{Introduction}

The importance of the intestinal microbiota for gastrointestinal (GI) functions and health has been shown in many studies with human subjects, but also with model animals such as mice and pigs ${ }^{(1,2)}$. In addition, several disease patterns in humans may be associated with the composition and/or metabolic activity of the intestinal microbiota. Relationships between variations in the abundance or metabolic activity of certain phyla and bacterial groups and the development of several medical conditions, such as obesity, have been established ${ }^{(1,3)}$. Other diseases related to changes in the composition and activity of the intestinal microbiota include diarrhoea and necrotising enterocolitis $(\mathrm{NEC})^{(4,5)}$. As diet composition reflects the substrates available for the intestinal microbiota, thereby affecting their composition and metabolic activity, dietary modulation appears to be a valuable and promising tool to improve host health by beneficially steering microbial composition and metabolism ${ }^{(6,7)}$. Therefore, dietary supplementation of food additives, such as probiotics, has been frequently proposed. Probiotic food supplements, i.e. viable micro-organisms, may alter the microbiota of the host, thus beneficially influencing its health $^{(8)}$, with Lactobacillus and Bifidobacterium species being among frequently used probiotics ${ }^{(9)}$. Additionally, non-digestible food ingredients such as oligosaccharides can be used as prebiotics to modulate the gut microbiota, as they have proven to stimulate the growth and/or activity of beneficial bacterial groups in the colon ${ }^{(10)}$.

In the past, rodents have been used most frequently as animal models. However, despite some advantages, such as their low costs in breeding, feeding and handling, several physiological and metabolic differences compared with humans have to be acknowledged. These differences include rodents being originally granivore animals in contrast to omnivorous humans, with fermentation taking place in their large caecum, while also practicing caecotrophy ${ }^{(11,12)}$. Furthermore, the rat as a small animal needs more feed per unit body weight (BW), which

\footnotetext{
Abbreviations: BTE, black tea extract; BW, body weight; CLA, conjugated linoleic acid; FOS, fructo-oligosaccharide; GI, gastrointestinal; GIT, gastrointestinal
} tract; HFA, human flora-associated; MCFA, medium-chain fatty acid; NEC, necrotising enterocolitis; OES, oral electrolyte solution. 
means a faster digesta passage rate and, in addition, often a lower capacity for fibre digestion compared with humans ${ }^{(13)}$. With respect to gut microbiota, the main bacterial groups such as Firmicutes and Bacteroidetes present in the faecal and caecal contents of rats and mice are similar compared with humans ${ }^{(14-16)}$. However, the abundance of important bacteria genera such as Lactobacillus and Bifidobacterium spp. differs between humans and rats $^{(17-19)}$

The pig as a human-sized, omnivorous animal with anatomical and physiological similarities to humans has been proposed as an alternative animal model for research into dietary modulation of the human gut microbiota ${ }^{(20,21)}$. Similar to humans, the gut microbiota of pigs mainly consists of the Firmicutes and Bacteroidetes phyla ${ }^{(22)}$. In this context, it has to be mentioned that the pig has already been used for a long time as an animal model for research into human nutrition and biomedicine ${ }^{(23)}$, as it has been described in several reviews comparing pigs with other animal models ${ }^{(24)}$. According to these authors, there are diverse areas of application for the pig model including amino acid metabolism, total parenteral nutrition, rotavirus infection, and bacterial and viral pneumonia. Puiman \& Stoll $^{(25)}$ reviewed the use of animal models to study neonatal nutrition in humans. They concluded that neonatal mice are suitable for mechanistic and genomic research in postnatal nutrition and associated diseases, while the neonatal pig is a suitable model to investigate acute and chronic effects of parenteral and enteral nutrition on whole-body metabolism in addition to specific tissues.

In order to assess the suitability of the pig as an appropriate model animal, a systematic comparison of the gut microbiota of pigs and humans is inevitable. In the present review, anatomical and physiological similarities and differences between the GI tract (GIT) of pigs and humans will be described, with special focus on the composition and metabolic activities of the microbiota harboured in the GIT of these two species. Studies in which the pig was used as a model to assess the role of the intestinal microbiota in disease development will be reviewed and, in particular, the impact of diet composition on the intestinal microbial community and its metabolic activity will be evaluated to identify beneficial effects on host health and recovery.

\section{Anatomy of the gastrointestinal tract and body} constitution - similarities and differences between humans and pigs

The porcine and human intestinal tracts are very similar with respect to anatomical and physiological characteristics $^{(23,26,27)}$. This includes comparable digesta transit times ${ }^{(23)}$ and analogous digestive and absorptive processes $^{(12)}$. Moreover, the minimum nutrient requirements of pigs are similar to recommended daily allowances of humans when expressed per $\mathrm{kg}$ of dietary $\mathrm{DM}^{(23)}$.
Additionally, when calculating the relationship between intestinal length and BW, intestinal length amounts to $0 \cdot 1 \mathrm{~m} / \mathrm{kg} \mathrm{BW}$, for both humans and pigs ${ }^{(28)}$. However, the two species differ in the total length of their intestinal tracts. In humans, the length of the small and large intestines is $5.5-7 \mathrm{~m}$ and $1.5 \mathrm{~m}$, respectively, at maturity (33 years) ${ }^{(29)}$, whereas the corresponding values in pigs amount to $15-22$ and $4-6 \mathrm{~m}$, respectively, at an assumed maturity age of 3 years ${ }^{(23,30)}$. Other anatomical differences include a more distinct separation between duodenum, jejunum and ileum in humans compared with pigs, and a different arrangement of the small and large intestines in the abdomen of the two species ${ }^{(31)}$.

When using pigs as an animal model for humans, the rapid growth and mature size of modern swine breeds $(90-120 \mathrm{~kg}$ and $330-450 \mathrm{~kg}$ at the age of 6 months and at the adult stage, respectively) to obtain maximal performance have to be taken into account when comparing the two species ${ }^{(32)}$. With regard to their body size, mini-pigs, with an adult BW of only $70-120 \mathrm{~kg}$, might be closer to humans, while also being easier to handle, though more expensive $^{(33)}$.

\section{Intestinal microbiota of humans and pigs: microbial fermentation and composition}

Both pigs and humans are colon fermenters, and they have a similar composition of the colonic microbiota ${ }^{(23)}$. However, symbiotic micro-organisms harboured in the GIT play a relatively minor role in the de novo synthesis of nutrients such as amino acids and fatty acids compared with ruminants ${ }^{(33)}$. Pigs exhibit significant caecal fermentation $^{(34)}$, and may obtain up to $30 \%$ of their energy requirement for maintenance from microbially produced SCFA in the large intestine ${ }^{(35)}$. On the contrary, humans lack a distinct caecum ${ }^{(36)}$, and only about $7 \%$ of their energy requirement for maintenance originates from SCFA produced in the colon ${ }^{(37)}$. In the GIT, SCFA and various gases $\left(\mathrm{H}_{2}, \mathrm{CO}_{2}\right)$ are the major metabolites produced by microbial fermentation ${ }^{(38)}$. The largest fraction of SCFA is acetate, propionate and butyrate, with acetate being the most prominent of the three major SCFA, making up approximately two-thirds of the total SCFA ${ }^{(39)}$. Acetate is extensively produced by various bacterial groups, while propionate and butyrate, which are known for their beneficial effects on the host ${ }^{(40)}$, are produced by a limited number of bacterial groups only. For example, propionate is largely metabolised in the liver where it is used as a precursor for gluconeogenesis and may inhibit lipogenesis ${ }^{(41,42)}$, while butyrate is the preferred energy source for the colonic epithelial cells ${ }^{(43)}$. Common butyrate producers in the GIT are clostridia such as Roseburia spp. and Eubacterium rectale ${ }^{(44)}$. Increased concentrations of SCFA in the GIT, especially acetate, are suggested to secure a preventive effect on the overgrowth of endogenous Escherichia coli ${ }^{(45)}$. 


\section{The human gut microbiota: a brief overview}

The composition of the intestinal microbiota in humans is extremely complex and therefore difficult to describe, and there exist plenty of data. The following section aims to provide a rather general and brief overview, thereby focusing on the major genera.

The human GIT contains about $10^{14}$ bacterial cells, with the highest density and diversity present in the large intestine ${ }^{(46,47)}$. These bacteria belong to the Firmicutes group (about 60\%), Bacteroidetes (about 15\%), followed by Actinobacteria (about 15\%), Verrucomicrobia (about 2\%), Proteobacteria (about 1\%) and Methanobacteriales (about $1 \%)^{(48,49)}$. In humans, the phylum Firmicutes comprises species belonging to the genera Eubacterium, Clostridium, Ruminococcus and Butyrivibrio ${ }^{(50)}$ with the Eubacterium rectale-Clostridium coccoides group being represented in large numbers of total bacteria, accounting for about $28 \%$ of total bacteria in faecal samples (Table 1$)^{(17)}$. Bacteroidetes are represented by genera related to Bacteroides, which are generally present in high numbers in the human gut microbiota, averaging 9 to $42 \%$ of total bacteria $^{(51)}$. Actinobacteria, the third most prevailing phylum in the human GIT, comprise the CollinsellaAtopobium group, with $0 \cdot 3-3 \cdot 7 \%$ of total bacteria ${ }^{(52,53)}$, and bifidobacteria. Bifidobacteria are known for their health-promoting properties ${ }^{(10)}$, and are used as probiotic food ingredients ${ }^{(54)}$, such as Bifidobacterium bifidum and Bifidobacterium longum ${ }^{(55)}$. They compose about $4 \%$ of the human faecal microbiota ${ }^{(17,53)}$.

Table 1. Proportions of bacteria in human faeces assessed by fluorescent in situ hybridisation combined with flow cytometry detection*

(Mean values and standard deviations)

\begin{tabular}{lrr}
\hline & \multicolumn{2}{c}{$\begin{array}{c}\text { Proportion of total } \\
\text { bacteria in faecal } \\
\text { sample (\%) }\end{array}$} \\
\cline { 2 - 3 } Probe & Mean & $\mathrm{SD}$ \\
\hline Clostridium coccoides-Eubacterium & $28 \cdot 0 \dagger$ & $11 \cdot 3$ \\
rectale (Erec 482) & $22 \cdot 0 \ddagger$ & $7 \cdot 6$ \\
Clostridium leptum (Clep 866) & $25 \cdot 2 \dagger$ & $7 \cdot 6$ \\
Bacteroides (Bac 303) & $21 \cdot 7 \S$ & $7 \cdot 7$ \\
& $8 \cdot 5 \dagger$ & $7 \cdot 1$ \\
Atopobium (Ato 291) & $9 \cdot 1 \ddagger$ & $6 \cdot 7$ \\
Bifidobacterium (Bif 164) & $3 \cdot 1 \dagger$ & $2 \cdot 8$ \\
& $3 \cdot 7 \ddagger$ & $2 \cdot 8$ \\
Lactobacillus-Enterococcus (Lab 158) & $4 \cdot 4 \dagger$ & $4 \cdot 3$ \\
Enterobacteria (Enter 1432) & $4 \cdot 1 \ddagger$ & $3 \cdot 9$ \\
Streptococcus (Strc 493) & $1 \cdot 8 \dagger$ & $1 \cdot 4$ \\
& $2 \cdot 0 \S$ & $1 \cdot 3$ \\
& $1 \cdot 0 \ddagger$ & $2 \cdot 8$ \\
& $0 \cdot 1 \S$ & $0 \cdot 1$ \\
& $0 \cdot 6 \dagger$ & $0 \cdot 8$ \\
& $0 \cdot 4 \S$ & $0 \cdot 6$ \\
\hline
\end{tabular}

* Donors on a Western European diet.

†Data compiled according to Lay et al. ${ }^{(17)}$. Age of donors: 7-52 years ( $n$ 91).

$\ddagger$ Data compiled according to Rigottier-Gois et al. ${ }^{(53)}$. Age of donors: $3-68$ years $(n 23)$

$\S$ Data compiled according to Lay et al. ${ }^{(56)}$. Age of donors: $25-45$ years $(n 21)$.
Table 2. Five most abundant bacteria families in piglets $(n 6)^{\star}$ (adapted from Petri et al. ${ }^{(67)}$ )

\begin{tabular}{lrcr}
\hline & \multicolumn{3}{c}{$\begin{array}{c}\text { Percentages of gene sequences } \\
\text { in sample (\%) }\end{array}$} \\
\cline { 2 - 4 } Family & $6 \mathrm{~h}$ & Day 20 & $\begin{array}{c}\text { Average } \\
6 \mathrm{~h}-20 \mathrm{~d}\end{array}$ \\
\cline { 2 - 4 } Lactobacillaceae & 1.5 & 44.6 & 23.3 \\
Clostridiaceae & 33.8 & 1.4 & 17.1 \\
Streptococcaceae & 1.5 & 5.4 & 15.4 \\
Enterobacteriaceae & 25.0 & 0.0 & 6.0 \\
Moraxellaceae & 8.8 & 2.7 & 3.5 \\
\hline
\end{tabular}

* Data for libraries prepared from three gastrointestinal tract locations (stomach, small intestine and hindgut) of piglets $(6 \mathrm{~h}-20 \mathrm{~d})$. Digesta collection at $6 \mathrm{~h}, 12 \mathrm{~h}$, and at days $1,2,3,5,10$ and 20 .

According to the results of representative studies as outlined in Table 1, lactobacilli may be present in colonic or faecal contents of humans to a lower extent, with levels comprising about $2 \cdot 0 \%$ of total bacteria ${ }^{(17,56)}$, or less $(0 \cdot 2-1 \cdot 0 \%)^{(57)}$. However, there exists a considerable variation between individuals as well ${ }^{(58)}$. Streptococci in the human microbiota occur in a similar range as lactobacilli, amounting to $0 \cdot 4-1 \cdot 6 \%$ of total bacteria $(17,56,59)$.

\section{The porcine gut microbiota}

Similar to humans, the gut microbiota of pigs mainly consists of the Firmicutes and Bacteroidetes phyla ${ }^{(22)}$. The main bacterial groups in the pig GIT comprise the following bacteria: Streptococcus spp., Lactobacillus spp., Eubacterium spp., Fusobacterium spp., Bacteroides spp., Peptostreptococcus spp., Bifidobacterium spp., Selenomonas spp., Clostridium spp., Butyrivibrio spp., Escherichia spp., Prevotella and Ruminococcus spp. ${ }^{(22,60-65)}$. Kim et $a{ }^{(66)}$ assessed the pig's microbiota in faecal samples, which were collected five times in 3-week intervals starting at the age of 10 weeks. According to their results, the two most abundant bacterial genera of the pigs are Prevotella spp. (11.6\% of total bacteria), belonging to the Bacteroidetes phylum, and Anaerobacter (10.4\%), members of the Firmicutes. Interestingly, the abundance of Prevotella spp. decreased, while that of Anaerobacter spp. increased, with the age of the animal.

In contrast to the human GIT, the population of bifidobacteria present in the GIT of pigs is considerably lower, amounting to less than $1 \%$ of total bacteria or being even undetectable ${ }^{(22)}$. This has been confirmed in intestinal samples (stomach, small intestine, hindgut) of piglets collected at the age of $6 \mathrm{~h}$ to $20 \mathrm{~d}$ after birth; the results of this study are tabulated in Table $2^{(67)}$. Pieper et al. ${ }^{(68)}$ analysed the gut bacteria in the small intestine of piglets at 1, 2, 5 and $11 \mathrm{~d}$ post-weaning and did not detect any bifidobacteria and Escherichia coli on day 11 post-weaning. In addition, Enterobacteriaceae and members of the Clostridium coccoides-Eubacterium rectale cluster were only found occasionally. According to a study of Loh et al. ${ }^{(69)}$, 
bifidobacteria could be detected in the jejunum, ileum, and in colon samples in less than $40 \%$ of the tested piglets. If they were present, Bifidobacterium spp. in the porcine intestine, such as Bifidobacterium suis, Bifidobacterium globosum or Bifidobacterium pseudolongum, differed from those generally found in the human $\operatorname{GIT}^{(70,71)}$. Nevertheless, the most abundant phylotypes of the pig are the lactic acid-producing bacteria, in particular lactobacilli ${ }^{(22)}$, in contrast to humans, yet there exists a considerable variation of Lactobacillus spp. numbers as influenced by the age of the host animal ${ }^{(66)}$. For example, in pigs at 10 weeks of age, lactobacilli averaged $11.0 \%$ of total bacteria, whereas in pigs at 22 weeks of age their content decreased to $3 \cdot 2 \%{ }^{(66)}$, as shown in Table 3 . In newborn piglets, $1.5 \%$ of sequence samples could be assigned to Lactobacillaceae in the first hours of life, while their numbers increased to $44.6 \%$ at day $20^{(67)}$. According to Krause et $a{ }^{(72)}$, who analysed Lactobacillus species in the pars oesophagus, ileum and caecum of weanling piglets, distribution of Lactobacillus in the GIT is also greatly influenced by the diet. In their study, relative abundance data indicated that L. brevis, L. fermentum and L. oris were by far the most abundant taxa. Also, L. plantarum was one of the predominant species isolated; however, it was only found in the pre-weaning period. According to Pieper et $a l .{ }^{(68)}$, L. sobrius/L. amylovorus became dominant species in the small intestine of piglets from day 1 to day 11 post-weaning, whereas the abundance of $L$. salivarius and L. gasseri/jobnsonii declined.

Compared with humans, the abundance of streptococci in faeces is higher in pigs, averaging $7 \cdot 4 \%$ of total bacteria $^{(66)}$, with increasing numbers in the first days of life $\mathrm{e}^{(67)}$. Moreover, the abundance of Bacteroides spp. in faecal samples appears to be much lower in the pig ( $0.1 \%$ on average), in contrast to humans, where they belong to the frequently occurring bacteria ${ }^{(51,66)}$. On the other hand, according to Guo et al. ${ }^{(2)}$, Bacteroides spp. averaged $3.8 \%$ of total bacteria in faeces of 5 -year-old (lean) Banna mini-pigs.

\section{Main determinants affecting intestinal microbiota composition}

Principally, composition of the gut microbiota depends on a variety of exogenous factors. Diet, age and environmental conditions are important determinants ${ }^{(73,74)}$, while in pigs sanitary conditions and coprophagy also play a significant role. Furthermore, the host's immune system exerts major impacts on the microbial ecosystem, which has been reviewed elsewhere (for example, Hooper et al. ${ }^{(75)}$ ).

Environment. At birth, the intestines of infants are sterile ${ }^{(76)}$; however, within a few hours, bacteria are detectable in faeces. Initially, these are facultative aerobes; thereafter, through consumption of oxygen by these bacteria, follows colonisation with strict anaerobes ${ }^{(76)}$. These bacteria mainly originate from the mother and the environment, with the mode of delivery being the major determinant of the composition of the intestinal microbiota. While vaginally born infants are colonised first by faecal and vaginal bacteria of the mother, caesarean section leads to colonisation with bacteria from the hospital environment and health care workers ${ }^{(76,77)}$. According to a study of Penders et al. ${ }^{(78)}$, caesarean section resulted in lower colonisation rates and counts of bifidobacteria and higher Escherichia coli counts, while hospitalisation was associated with higher colonisation rates of Clostridium difficile. In pigs Clostridium difficile is well adapted to the intestinal tract irrespective of the environmental conditions, which means that no differences could be observed in intestinal Clostridium numbers when comparing an indoor- with an outdoor production system ${ }^{(79)}$.

In infants, the intestinal microbiota has been found to be influenced by the environment during birth, prematurity, hygiene measures, and the type of infant feeding ${ }^{(80)}$. In this context, the number of siblings has been suggested to play a role, since a greater proportion of bifidobacteria was found in infants with older siblings compared with those without siblings ${ }^{(78)}$. On the other hand, a relationship between the composition of the gut microbiota and the

Table 3. Five most abundant bacteria in pig faeces ${ }^{*}$ and proportions of Roseburia, Clostridium, Bifidobacterium and Bacteroides ( $n$ 10) (adapted from Kim et al. ${ }^{(66)}$ )

\begin{tabular}{lccccc}
\hline & \multicolumn{5}{c}{ Sequences in faecal samplest (\%) } \\
\cline { 2 - 6 } Genus & Week 10, trial 1 & Week 10, trial 2 & Week 22, trial 1 & Week 22, trial 2 & $\begin{array}{c}\text { Trials } \\
\text { 1 and 2 average } \\
\text { (10-22 weeks) }\end{array}$ \\
\hline Prevotella & 29.1 & 23.0 & 3.6 & 4.0 & 11.6 \\
Anaerobacter & 1.1 & 0.1 & 26.6 & 21.9 & 10.4 \\
Streptococcus & 5.7 & 3.6 & 2.5 & 6.0 & 7.4 \\
Lactobacillus & 9.7 & 12.2 & 3.7 & 2.7 & 7.0 \\
Coprococcus & 3.4 & 3.0 & 4.3 & 4.9 & 1.4 \\
Roseburia & 0.6 & 0.9 & 1.7 & 0.9 & 1.3 \\
Clostridium & 0.08 & 0.02 & 1.2 & 1.6 & 0.6 \\
Bifidobacterium & 0.3 & 0.4 & 0.1 & 0.1 & 0.1 \\
Bacteroides & 0.0 & 0.1 & 0.1 & 0.1 & 0.1 \\
\hline
\end{tabular}

* Pigs (age 10-22 weeks) on a commercial diet based on maize and soyabean meal.

†Collection of samples: weeks 10,13,16, 19 and 22. The average Shannon-Weaver and Simpson index values per group were 5.74 (SD 0.35) and 0.97 (SD 0.02) for farm (trial) 1, and 6.17 (SD 0.18) and 0.98 (SD 0.01) for farm (trial) 2. 
presence of furry pets or farm residence could not be shown $^{(78)}$.

Nutrition. The high impact of nutrition on the microbiota in neonates is obvious since earlier colonisation with bifidobacteria has been shown in breast-fed infants compared with in infants fed with formula ${ }^{(81)}$. This is probably due to the presence of oligosaccharides in human milk that exhibit growth-promoting effects on bifidobacteria $^{(82,83)}$. In Table 4 , proportions of bacteria in infant faecal samples are summarised, with the Bifidobacterium genus accounting for $40-75 \%$ of the total detectable bacteria $^{(22,84)}$. The milk itself contains bacteria as well, with an estimated intake of $1 \times 10^{5}$ to $1 \times 10^{7}$ bacteria, based on daily consumption of $800 \mathrm{ml} \mathrm{milk}{ }^{(85)}$. In particular, staphylococci and streptococci have been detected, with Staphylococcus epidermidis, Streptococcus salivarius and Streptococcus mitis being most prevailing ${ }^{(85,86)}$, although maternal skin contact while breast-feeding could have been responsible for their prevalence as well ${ }^{(86)}$. As these bacteria have also been documented in stool samples of breast-fed infants ${ }^{(87,88)}$, it can be speculated that the bacterial composition of breast milk reflects infant faecal microbiota. In pigs, the bacterial community of the GIT also adapts to changes in the animal's diet, as has been observed following the feeding of different experimental diets ${ }^{(73)}$; diet has an influence on the distribution of the microbiota in the GIT too, as described by Krause et $a l{ }^{(72)}$ for lactobacilli.

Age. The impact of age on gut microbiota composition has been observed by Mariat et al. ${ }^{(74)}$, who confirmed the dominance of bifidobacteria in the microbiota of infants. In addition, higher proportions of lactobacilli in infants compared with seniors, and lower percentages of Clostridium leptum and Clostridium coccoides in infants than in adults, have been reported by Mariat et al. ${ }^{(74)}$. Moreover, these authors determined an increase in Escherichia coli in seniors compared with adults. In pigs, differences in bacterial numbers as influenced by progressing age were

Table 4. Proportions of bacteria in infant faecal samples (age 6 weeks) from five European Union countries assessed by fluorescent in situ hybridisation combined with flow cytometry (n 606) (adapted from Fallani et al. ${ }^{(59)}$ )

(Mean values and standard deviations)

\begin{tabular}{lcr}
\hline & \multicolumn{2}{c}{$\begin{array}{c}\text { Proportion of total } \\
\text { detectable bacteria } \\
\text { in faeces (\%) }\end{array}$} \\
\cline { 2 - 3 } Bacterial groups, genera and species & Mean & SD \\
\hline Bifidobacterium genus & 40.0 & 30.6 \\
Bacteroides group & 11.4 & 17.6 \\
Enterobacteria group & 7.5 & 15.9 \\
Clostridium coccoides group & 5.5 & 11.5 \\
Clostridium perfringens + & 3.0 & 8.4 \\
$\quad$ Clostridium difficile sp. & & 6.2 \\
Atopobium cluster & 2.1 & 3.5 \\
Lactoptococcus group & 1.6 & 4.0 \\
Clostridium leptum group & 1.2 & 2.3 \\
\hline
\end{tabular}

obtained as well. According to Petri et al. ${ }^{(67)}$, Clostridiaceae accounted for $34 \%$ of total sequences in piglets $6 \mathrm{~h}$ after birth, while only $1 \%$ was found at week 22 of age (Table 2) ${ }^{(67)}$. In the same study, Enterobacteriaceae could not be detected at day 20 of age. In another study ${ }^{(89)}$, however, Enterobacteriaceae counts were in a steady state from the day of weaning ( $28 \mathrm{~d}$ of age) until day 5 post-weaning, whereas significantly lower counts were found on day 11 post-weaning. Similarly, in 10-week-old pigs, $26 \%$ on average of total sequences in faeces could be assigned to Prevotella spp., while in week 22, abundance decreased to about $4 \%$ (Table 3$)^{(66)}$.

Sanitary conditions and coprophagy. In piglets, the influence of sanitary conditions on gut microbiota composition has been established ${ }^{(90)}$. Faeces of piglets raised under poor sanitary conditions (facilities not disinfected or cleaned after previous occupancy with pigs from the same herd) compared with faeces of animals kept in a clean environment contained significantly more Lactobacillus spp. and enterobacteria ${ }^{(90)}$. In addition, fewer anaerobic sulfite-reducing bacteria were present, which are considered detrimental bacteria due to their production of hydrogen sulfide which, in turn, may damage the intestinal epithelium ${ }^{(90)}$. Furthermore, poor sanitary conditions may stimulate butyrate production ${ }^{(90)}$, which is assumed to be beneficial for the host ${ }^{(91)}$. Most likely, butyrate production can be attributed to the presence of lactobacilli, since these bacteria produce lactate, which, in turn, is utilised by butyrate-producing bacteria ${ }^{(92)}$.

Coprophagy has been observed by Watson \& Bertram ${ }^{(93)}$ in intensively reared sows, and Gleed \& Sansom ${ }^{(94)}$ reported the consumption of faeces by piglets through behaviour such as suckling an udder covered with faeces and rubbing littermate's bodies. This might explain to a certain degree existing differences in the composition of the microbiota between pigs and humans, since environmental conditions and resultant behaviour patterns between pigs and humans differ significantly. Nevertheless, principal differences between the gut microbiota of humans and pigs have to be considered as well. Schmidt et al. ${ }^{(95)}$ found Streptococcus spp. and diverse Lactobacillus strains (L. reuteri, L. amylovorous, L. johnsonii, L. brevis, L. pentosus and L. plantarum) in the ileum of isolator-reared piglets. Of total clones, piglets transferred to the isolator $2 \mathrm{~d}$ after birth from an indoor rearing facility contained $27 \cdot 4 \%$ Lactobacillaceae-affiliated clones ${ }^{(95)}$, which in this case cannot be attributed to pig-specific environmental conditions or behaviour patterns.

Role of the intestinal microbiota in host health and disease development and its dietary modulation in studies with pigs

The use of pigs as a relevant human medical model is well documented $^{(96)}$. Also, pigs and humans share similarities in GI microbial diversity ${ }^{(97)}$. In comparison with other animal 
models including rodents, pigs allow for more invasive sampling in the GIT, induction of disease states, and a variety of nutritional intervention approaches. Thus, several studies have used the pig model when investigating disease states related to the intestinal microbiota, and their possible modulation by dietary means. These include studies on weanling diarrhoea, first of all, since piglets naturally are susceptible to weanling diarrhoea similar to human infants, and, second, since pigs may be used as suitable animal models when experimentally inducing secretory diarrhoea to assess possible effects of feed/food additives such as pre- or probiotics. Due to the development of very similar symptoms and course of disease in both infants and piglets, studies on the dietary treatment of NEC will be considered in the following review as well. Finally, in line with recent concern on the possible relationship between intestinal microbiota and the development of obesity, the present review will also focus on studies on this chronic disease, thereby revealing possibilities to modulate the gut microbiota beneficially. As for the latter, while studies have mainly been performed with rodent models, the alternative use of the pig will be reviewed.

\section{Diarrhoea: occurrence after weaning in human infants and piglets}

For infants, the time of introduction of food other than breast milk is a high-risk period due to the occurrence of diarrhoeal diseases, which represent a main health problem worldwide, affecting primarily neonates and children ${ }^{(98,99)}$. This so-called 'weanling diarrhoea'(100) is accompanied by shifts in the composition of faecal microbiota $^{(5)}$, indicating changes in the intestinal microbiota of the infant due to dietary modifications. As a result, an increased susceptibility to infectious diseases has been observed $^{(101)}$. It has been shown that 10 to $30 \%$ of cases of sporadic endemic infant diarrhoea occurred following an enterotoxigenic Escherichia coli infection ${ }^{(102)}$, producing enterotoxins and attaching to enterocytes ${ }^{(103)}$. On the other hand, feeding breast milk protects against diarrhoea, firstly by minimising the infant's exposure to contaminated foods and fluids ${ }^{(104)}$. Second, it may reduce the incidence and severity of infections in the infant by synergistic actions of several bioactive molecules present in colostrum and milk, including immunocompetent cells, immunoglobulins, fatty acids, polyamines, oligosaccharides, lysozyme, lactoferrin and other glycoproteins, as well as antimicrobial peptides ${ }^{(105)}$. Furthermore, mother's milk may be considered as a source of potentially beneficial bacteria, such as certain Lactobacillus spp., protecting mothers and/or infants against a variety of allergic, inflammatory and infectious diseases ${ }^{(106)}$.

For piglets, the weaning transition is a complex period during which they have to cope with abrupt separation from their mother, mixing with other litters in a new environment, and switching from highly digestible milk to less digestible, more-complex solid feed. Sows' milk, similar to human milk, provides several protecting factors, including maternal cells such as phagocytes, lymphocytes and epithelial cells, as well as antimicrobial substances, for example, lactoferrin and lysozyme ${ }^{(107)}$. Additionally, the probiotic potential of certain bacterial species in the milk, such as L. reuteri, has been demonstrated ${ }^{(108)}$. Consequently, weaning means the withdrawal of these defensive factors in the milk, while the weaning period is generally accompanied by morphological, histological and microbial changes in the GIT of young animals ${ }^{(109,110)}$. Enteropathogenic bacteria and their interactions in the small intestine represent an additional burden for the newly weaned piglet $^{(110)}$. Studies with piglets have shown that not only haemolytic enteropathogenic Escherichia coli, but also rotavirus, one of the major viral agents accountable for the development of diarrhoea, are responsible for the outbreak of this disease ${ }^{(111)}$. In humans, rotavirus is the most important reason for diarrhoea hospitalisation among children $^{(112)}$, and causes 440000 deaths annually in children below 5 years of age worldwide ${ }^{(113)}$. Lecce et al. ${ }^{(111)}$ concluded in their study with piglets that by damaging the epithelium of the small intestine, which is frequently associated with malabsorption, this virus creates the required environment for the subsequent colonisation and growth of Escherichia coli. However, it has to be considered that the severity and localisation of rotavirus infections may vary among animal species and between studies. Moreover, some rotavirus infections are asymptomatic, which suggests that both viral and host factors can affect disease severity ${ }^{(114)}$.

Dietary strategies as therapeutic tools for diarrhoeal diseases. Several dietary tools targeting the intestinal microbiota, thereby acting as a prophylactic option in the prevention of diarrhoea, are currently under investigation, including probiotics and prebiotics ${ }^{(115,116)}$. While multiple studies have been performed investigating the effect of feed additives, such as probiotics, on weanling diarrhoea in piglets with the aim of improving production conditions $^{(117)}$, the effect of specific food additives in alleviating diarrhoea has been assessed using human subjects as well ${ }^{(118)}$. In addition, pigs have also been used to examine the potential of these supplements to influence human health beneficially ${ }^{(115)}$.

As a possible mechanism for probiotics to alleviate or prevent diarrhoea, enhancing immune responses has been suggested. For example, immune function-enhancing effects have been shown for the probiotic Bifidobacterium lactis HN019 in studies with mice ${ }^{(119)}$ and human subjects ${ }^{(120)}$. Accordingly, in a study using a piglet model of weanling diarrhoea ${ }^{(115)}$, animals that received Bifidobacterium lactis HN019 showed lower concentrations of faecal rotavirus and Escherichia coli, higher blood leucocyte phagocytic and T-lymphocyte proliferate responses, and higher GIT pathogen-specific antibody titres. These piglets 
also showed a lower severity of weanling diarrhoea and an improved feed conversion ratio during weaning, compared with control piglets not receiving the probiotic. The authors assumed a mechanism of enhanced immunemediated protection, and suggested similar beneficial effects for the probiotic use in infants ${ }^{(115)}$.

The health-promoting effect of probiotics was also confirmed in a study using a pig model of secretory diarrhoea $^{(121)}$, i.e. diarrhoea produced by an increase in colonic secretions ${ }^{(122)}$. Here, the dietary supplementation of the probiotic strain Escherichia coli Nissle 1917 exhibited protective effects against diarrhoea caused by the toxigenic Escherichia coli strain Abbotstown ${ }^{(121)}$. This strain was administered via an orogastric tube to establish a pig model of secretory diarrhoea ${ }^{(121)}$. Along with the clinical signs of diarrhoea, jejunal epithelia tissues of animals that did not receive the probiotic showed an increased secretory response after stimulation of the cyclic AMP-mediated second messenger pathway by forskolin. This indicates an increased excitability of chloride secretory systems under infected conditions ${ }^{(121)}$. In Ussing chamber experiments, forskolin is often used with intestinal tissues from different species including the pig to induce a secretory response, specifically via cyclic AMP-mediated $\mathrm{Cl}^{-}$secretion ${ }^{(123-125)}$. Pretreatment with the probiotic strain Escherichia coli Nissle 1917 completely abolished clinical signs of secretory diarrhoea, and the jejunum epithelia of these animals did not exhibit an increased secretory response upon stimulation with forskolin ${ }^{(121)}$.

Furthermore, the use of prebiotics has been suggested to improve host health by beneficially influencing the composition and metabolic activity of the gut microbiota. In this context, the beneficial effects of inulin on the gut microbiota in human subjects have been described, particularly by enhancing colonic bifidobacteria numbers, although results may vary probably due to variations in chain length and dosage of the type of inulin used ${ }^{(10)}$. For example, in a study of Patterson et al. ${ }^{(126)}$ with pigs, a short-chain inulin product was already partly fermented in the jejunum and ileum. In contrast, long-chain inulin was not degraded until reaching the distal ileum or the caecum $^{(126)}$

Increased numbers of bifidobacteria have been detected upon dietary supplementation with prebiotic fructooligosaccharides (FOS) in studies with human subjects $^{(10,127)}$, while infant formula supplemented with a mixture of galacto-oligosaccharides and FOS resulted in higher faecal counts of bifidobacteria and lactobacilli compared with infants fed unsupplemented formula ${ }^{(78)}$. According to Donovan et al. ${ }^{(128)}$, human milk oligosaccharides may be responsible for the differences in development, microbiota and incidence of disease between breast-fed and formula-fed infants, due to their abundance and diversity, large physiological actions and absence in infant formula. Polydextrose has been proposed as a surrogate for human milk oligosaccharides, and displayed prebiotic properties in a study with suckling piglets by increasing ileal lactobacilli and propionic and lactic acid concentrations and decreasing $\mathrm{pH}$ with associated alterations in ileal cytokine expression ${ }^{(129)}$. Furthermore, its safety as a food additive has been assessed, with measurements of diverse morphological, histological and biochemical parameters indicating that the supplementation of formula with polydextrose between $1.7 \mathrm{~g} / 1$ $(1.0 \mathrm{~g} / \mathrm{kg} \mathrm{BW}$ per $\mathrm{d})$ and $17 \mathrm{~g} / 1(8.35 \mathrm{~g} / \mathrm{kg} \mathrm{BW}$ per $\mathrm{d})$ does not show any toxicological effects on neonatal pigs, further supporting the safe use of this prebiotic carbohydrate in the nutrition of human neonates ${ }^{(130)}$.

In a pig model, FOS has been tested for its beneficial effects on secretory diarrhoea. Cholera toxin-inducing secretory diarrhoea was evaluated in 21-d-old pigs treated with FOS in combination with oral electrolyte solutions (OES) ${ }^{(20)}$. In healthy piglets, supplemental OES in combination with FOS increased the numbers of lactobacilli in most parts of the GIT (colon, caecum, mid-small intestine), but mostly in the colon, with 50-fold increased counts relative to normal healthy pigs without supplementation ${ }^{(20)}$. In piglets administered the diarrhoea-inducing cholera toxin, the addition of OES and FOS did not result in a reduction of diarrhoea and the associated loss of water. Thereafter, during the recovery phase from diarrhoea, piglets treated for $24 \mathrm{~h}$ with OES and FOS responded to this supplementation with higher proliferation rates of lactobacilli, especially in the colon. Compared with healthy piglets and recovering animals treated with OES solely, the supplementation of OES + FOS led to significantly higher densities of lactobacilli after $24 \mathrm{~h}$ in all samples (colon, caecum, mid-small intestine) of these piglets ${ }^{(20)}$.

Furthermore, research concerning diarrhoea caused by carbohydrate malabsorption in patients during enteral feeding has been carried out using the pig as a model. Kien et $a l .{ }^{(131)}$ applied inulin as a fermentable carbohydrate that does not cause osmotic diarrhoea before inducing diarrhoea in pigs following lactulose malabsorption. With regard to humans, administering inulin should potentially prevent diarrhoea caused by lactulose malabsorption following enteral feeding. In addition, inulin might attenuate some of the unfavourable effects of severe lactulose malabsorption ${ }^{(132)}$. Inulin, with an average of thirty-five fructosyl units, is supposed to show much less of an osmotic effect on the colon compared with lactulose $\mathrm{e}^{(131)}$. By prefeeding the prebiotic inulin, diarrhoea caused by the application of lactulose could be relieved $^{(131)}$. These findings are in agreement with observations of Flourie et al. ${ }^{(133)}$, who showed that primarily offering adult human subjects a low dose of lactulose increases fermentation and moderates diarrhoea during a period following a high dose of lactulose consumption. It appears that pre-feeding represents a form of adaption of the colonic microbiota, since a dose of indigestible carbohydrate that can be completely fermented might increase 
the overall capacity for fermentation, partly by inducing the production of bacterial glucosidases ${ }^{(133)}$.

In addition to pre- and probiotic applications, other feed additives might beneficially influence host health as related to diarrhoeal disease. Torrallardona et al. ${ }^{(134)}$ evaluated spray-dried animal plasma as an alternative to antimicrobial medication with colistin sulfate in weanling pigs challenged with Escherichia coli K99. The performance response to spray-dried animal plasma was similar to that obtained with the antibiotic colistin; thus, spray-dried animal plasma may be a suitable alternative to the use of antibiotics. The length of the villi could be maintained, and a higher smallintestinal weight was observed following the application of both products. Furthermore, they also had a direct effect on the microbial population of the GIT, with plasma supplementation stimulating the growth of lactobacilli in the ileum and caecum ${ }^{(134)}$. Other studies revealed positive effects of black tea extract (BTE) or green tea extract on GIT function of mice (ex vivo), calves and pigs ${ }^{(135-137)}$, including beneficial effects of dietary green tea extract or polyphenols on the gut microbiota of both animals ${ }^{(138-140)}$ and human subjects ${ }^{(141)}$. Moreover, there is evidence that flavonoids from both black and green tea possess antimicrobial properties against several pathogenic bacteria including pathogenic strains of Escherichia coli ${ }^{(142)}$, by removing Fe from Fe-dependent pathogens including Escherichia coli ${ }^{(143)}$. Recently, the effects of BTE on the prevalence of diarrhoea in a model of enterotoxigenic Escherichia coli-infected post-weaning piglets were assessed $^{(144)}$. In this study, dietary BTE supplementation decreased diarrhoea frequency in piglets by $20 \%$ throughout an experimental period of $27 \mathrm{~d}$. However, at the same time feed intake and feed efficiency were reduced by 16 and $12 \%$, respectively, as piglets preferred the control over the BTE-containing diets ${ }^{(144)}$, probably due to the presence of astringent theaflavins in tea ${ }^{(145)}$. Since no correlation could be obtained between feed intake and the occurrence of diarrhoea, the lower incidence of diarrhoea was associated with BTE supplementation rather than with reduced feed intake ${ }^{(144)}$. In vitro, Bruins et al. ${ }^{(144)}$ observed a $24 \mathrm{~h}$ delay at least in the exponential growth of enterotoxigenic Escherichia coli cultures following the addition of BTE. In conclusion, despite the anti-nutritional properties of BTE, further studies are warranted to develop a suitable mode of application of BTE in the treatment of diarrhoea ${ }^{(144)}$.

\section{Necrotising enterocolitis}

The GI inflammatory disorder NEC represents one of the most serious diseases for preterm neonates. Early symptoms of this disease are abdominal distension, food intolerance, regurgitation and lethargy, in both human infants and piglets ${ }^{(146,147)}$. Pathological changes in the intestinal wall occur mostly in the distal small intestine and colon of infants and piglets, resulting in the necrosis of the complete mucosa ${ }^{(148,149)}$. Pneumatosis intestinalis is a further symptom of NEC in infants as well as in pigs, which has been described as an accumulation of gas produced by bacteria ${ }^{(150)}$. Many factors play a role in disease progression in preterm neonates (human and pig) such as nutritional and immunological dysfunction as well as bacterial colonisation $^{(151)}$. However, potential interactions among these variables remain unclear. The immature intestine conditions may result in accumulated undigested food, eventually resulting in bacterial overgrowth and exaggerated fermentation ${ }^{(151)}$. In this context, the abundance of Escherichia coli, Klebsiella (duodenal aspirates) and Clostridium spp. (stool samples) is often assumed to be associated with the incidence of NEC in infants ${ }^{(152,153)}$. Studies with germ-free pigs revealed that NEC does not occur in the absence of bacteria ${ }^{(147,154)}$. Principally, the application of broad-spectrum antibiotics in caesareandelivered preterm pigs, administered together with formula, could prevent the development of NEC; however, several species, which are commonly associated with human infections, can survive the antibiotic treatment, and overgrowth of these species could potentially result in intestinal inflammation and necrosis ${ }^{(155)}$. Therefore, broad-spectrum antibiotics may prevent NEC in the short term, but may lead to an increased risk of NEC in the long term due to overgrowth of pathogens ${ }^{(155)}$. In infants and pigs, especially the occurrence of Clostridium perfringens seems to be associated with an increased frequency of $\mathrm{NEC}^{(147,153)}$. Nevertheless, inducing NEC by the inoculation of preterm pigs with Clostridium perfringens type A failed $^{(155)}$, and, in addition, Clostridium perfringens type $\mathrm{C}$ and $\mathrm{D}$ toxin immunisation of the preterm piglets did not protect against NEC in this study ${ }^{(155)}$. Thus, the presence of Clostridium perfringens in NEC may be a response to disease rather than a cause ${ }^{(155)}$.

In comparison with the pig, in humans the functional maturation of the GIT starts early after birth, but progresses slowly over time ${ }^{(156)}$. Therefore, the newborn is able to digest significant quantities of non-milk carbohydrates and proteins additionally to nutrients contained in milk $^{(156)}$. In contrast, in the pig, functional development of the gut takes place both pre- and postnatally ${ }^{(156)}$, resulting in a less developed GIT at birth when compared with human infants. At peak lactation of the mother, the gut capacity of piglets is about twice as high as that of the human infant, though both show similar $\mathrm{BW}^{(157)}$. Nevertheless, the advantage of the preterm piglet as a model animal to study NEC symptoms results from the very similar clinical and histological characteristics of this syndrome compared with the infant, together with an analogous development of the symptoms ${ }^{(158)}$. Furthermore, the possibility to apply 'total parenteral nutrition' in neonatal piglets is of further advantage, since it is considered to promote intestinal sickness and NEC in preterm infants ${ }^{(159)}$.

Dietary strategies as therapeutic tools for necrotising enterocolitis. The high impact of nutrition and environment on the intestinal microbiota of preterm infants is 
reflected in the microbial composition of stool samples of infants in their first week after birth: while formula-fed infants on day 6 after birth exhibit relatively high levels of enterobacteria, compared with lower numbers of bifidobacteria, in breast-fed infants bifidobacteria usually become dominant during the first week of life ${ }^{(81)}$. Additionally, preterm birth and formula feeding are associated with a predisposition for variations in the composition of the faecal microbiota and frequency of NEC compared with full-term neonates and infants receiving mother's milk $^{(4,78)}$. Thus, it has been suggested that dietary supplementation with probiotics might be a preventive option against the development of NEC. Generally, an enhanced proliferation of beneficial members of the GIT microbial ecosystem, together with favourable effects on intestinal permeability, intensified reaction of the intestinal immune system, and increased production of anti-inflammatory cytokines, is associated with diverse probiotic modes of $\operatorname{action}^{(160)}$.

In a piglet model, a probiotic treatment consisting of a mixture of Bifidobacterium animalis and four Lactobacillus species (L. acidophilus, L. casei, L. pentosus and L. plantarum) reduced NEC severity and mucosal atrophy and disorder when being administered together with formula instantly after delivery ${ }^{(159)}$. Moreover, growth of lactobacilli was significantly enhanced in the stomach, the small intestine and the colon, while the abundance of the potential pathogen Clostridium perfringens diminished significantly in the small intestine and colon ${ }^{(159)}$. In the same study, proliferation of coliforms was slightly reduced, and enterococci decreased significantly in the stomach and small intestine. Principally, the growth of these bacteria is stimulated following formula feeding ${ }^{(4)}$, and they have been identified as potential pathogens in human preterm neonates ${ }^{(161,162)}$. According to the study of Siggers et $a l .{ }^{(159)}$, piglets fed formula without the addition of probiotics showed a noticeable increase in the occurrence of NEC and severity of clinical symptoms. It has been suggested that octanoic acid might have been responsible for the higher incidence of stomach NEC in piglets fed with the formula diet, as only small amounts of this acid were present in the formula diet, but higher concentrations of octanoic acid were found in the stomach of the piglets ${ }^{(159)}$. In contrast, in piglets fed with the formula diet supplemented with probiotics, significantly lower levels of gastric octanoic acid were determined. Obviously, octanoic acid represents a metabolite resulting from gastric digestion and fermentation of the medium-chain TAG fraction of the diet, with higher amounts possibly being responsible for the increased rate of NEC occurrence $^{(163,164)}$. It appears that the reduction of octanoic acid concentration in the gastric lumen as observed in the study of Siggers et al. ${ }^{(159)}$ can be attributed to the dietary supplementation of probiotics, resulting in potential protection against NEC. This feature of probiotics is of special interest for the protection of the vulnerable small intestine and colon of preterm neonates, but more research is warranted to further elucidate these probiotic characteristics. Concerning medium-chain fatty acids (MCFA), it has also been shown that MCFA-containing fat sources and lipolytic enzymes could be a valuable alternative to nutritional antibiotics in piglets ${ }^{(165)}$. In the study of Dierick et $a l^{(165)}$, the antimicrobial effects of MCFA from three selected MCFA-containing fat sources and one appropriate microbial lipase were investigated in an in vitro model, finding that a minimal concentration of 0.025 m-MCFA in the medium (for example, stomach, proximal gut) seems to be necessary to achieve a significant ( $>10$-fold) bacterial suppression. Changes in microbial ecology due to the ingestion of MCFA have also been investigated by Zentek et al. ${ }^{(166)}$, who measured higher concentrations of caprylic (octanoic) and capric (decanoic) acid in the stomach of piglets fed MCFA diets, uncoated or coated with vegetable fat and lecithin, compared with a control group. Ingestion of MCFA diets led to an increase in the number of eubacteria, Enterobacteriaceae, clostridial clusters I and IV, L. johnsonii and L. amylovorus in gastric contents. Changes in concentrations of SCFA could also be observed, with lower levels of propionic, $n$-butyric and isovaleric acid and numerically higher concentrations of acetic acid in the small intestine. Ammonia concentrations increased in the distal small intestine of the MCFA groups. Obviously, MCFA can influence microbial ecology in the stomach and bacterial metabolites in the small intestine ${ }^{(166)}$

Interestingly, the development of NEC is assumed to be linked to higher levels of SCFA in the premature human intestine ${ }^{(167)}$, and the administration of SCFA can cause mucosal injury in rats ${ }^{(168)}$. Moreover, Cilieborg et al. ${ }^{(155)}$ determined significantly higher concentrations of acetate in the stomach, and significantly more acetate and butyrate in the colon of piglets with NEC compared with healthy animals. Butyrate has been shown to increase mucosal injury by enhancing the production of stromelysin-1 in cytokine-stimulated gut mesenchymal cells ${ }^{(169)}$. Generally, high levels of clostridia have been linked with the production of butyric acid, while bifidobacteria, by causing a decrease in clostridia numbers, have been associated with a decrease or disappearance of butyric acid ${ }^{(170)}$ Furthermore, it has been reported that the application of probiotic bifidobacteria reduced both the incidence and severity of NEC in premature neonates ${ }^{(171,172)}$

The positive results on the incidence of NEC following the application of probiotics in pigs have been confirmed in human subjects ${ }^{(160,172,173)}$. However, studies with preterm piglets also indicated that viable or inactivated probiotic strains (Bifidobacterium animalis, L. paracasei and Streptococcus thermophiles) increased the incidence and severity of $\mathrm{NEC}^{(174)}$. Moreover, bacteraemia and sepsis have been attributed to an applied Lactobacillus strain in a 6-week-old infant and a 6-year-old child ${ }^{(175)}$ and sepsis secondary to probiotic Bifidobacterium breve administration has been observed by Ohishi et al. ${ }^{(176)}$ 
As preterm neonates are primarily colonised by bacteria of low diversity, and because their gut immune system is immature, hypersensitivity of the intestine to administration of probiotic bacteria may occur, which is consistent with increased bacterial translocation and neonatal mortality in immunodeficient mice after probiotic administration $^{(174,177)}$. Thus, under certain conditions, some probiotic strains may be harmful for immunocompromised patients with disturbed gut function ${ }^{(174)}$.

Further studies have to be conducted before establishing routine probiotic supplementation to premature neonates, since factors such as the optimal dose, strain(s), timing and duration of administration, and side effects have not yet been sufficiently investigated ${ }^{(178)}$. Also, previous studies have only focused on a few strains of Bifidobacterium, Lactobacillus and Streptococcus, suggesting the need for the assessment of other possible probiotic candidates ${ }^{(151)}$, as well as the application of a suitable animal model such as the pig.

\section{Obesity}

Nowadays, obesity has become one of the major health issues, with 1.4 billion overweight adults, 20 years and older, and almost 500 million of them being obese in the year $2008^{(179)}$. The disease comes along with chronic inflammation, type 2 diabetes, CVD and certain types of cancer $^{(180)}$. According to the $\mathrm{WHO}^{(179)}, 65 \%$ of the world's population live in countries where being overweight or obese accounts for more deaths than underweight. Since humans are adapted to a situation of insufficiency of energy-dense foods, and the body is better prepared to protect against weight loss than weight gain, the oversupply of such foods is the main factor causing obesity ${ }^{(9)}$. Genetic factors may play a role as well, but an unhealthy lifestyle including so-called modern ways of nutrition such as fast food consumption, usually low in dietary fibre but high in fat and sugar, together with a lack of physical activity undoubtedly contributes to its development. Furthermore, dietary intake also affects gut ecology and bacterial composition, potentially contributing to the development of the disease as well $^{(181)}$. According to recent studies carried out with rodents and human subjects, differences in the gut microbiome of obese and non-obese subjects, and diet-dependent changes in the bacterial composition could be shown ${ }^{(3,7)}$. Apparently, differences in microbial composition are correlated with changes in its metabolic function, as in obese rodents increased levels of fermentation endproducts and lower energy contents were detected in the faeces, in comparison with non-obese animals ${ }^{(1)}$. An obesity-associated microbiota seems to increase fermentation of polysaccharides, which actually results in an enhanced energy yield for the host ${ }^{(1)}$. In human studies, butyrate levels in stool samples were lower in lean participants ${ }^{(182)}$, and the number of butyrate-producing bacteria (Firmicutes phyla) decreased following the consumption of a diet designed to induce weight loss ${ }^{(7,183)}$. Differences in the gut microbiota composition between lean and obese individuals have been studied in rodents and human subjects. In mice, higher numbers of the bacterial phylum Firmicutes were present in obese subjects in comparison with normal or lean animals. Of Bacteroidetes, lower numbers were generally observed in obese mice ${ }^{(1,3)}$, which corresponds to findings in human subjects ${ }^{(184)}$. Moreover, lower quantities of the Bifidobacterium group were found in overweight humans ${ }^{(182)}$, and there is evidence that reduced colonisation of the GIT with bifidobacteria in early childhood is correlated with obesity ${ }^{(185)}$.

However, inconsistencies between the results of these studies have to be acknowledged, as summarised in Table $5^{(1,7,182)}$. For example, Bacteroidetes numbers were found to be lower in obese compared with lean mice ${ }^{(1)}$, while they occurred in higher numbers in obese compared with lean human subjects in the study of Schwiertz et $a l{ }^{(182)}$, but were less abundant in obese humans according to Turnbaugh et al. ${ }^{(184)}$. Possible reasons for these discrepancies might result from the use of rodent models on the one hand due to limitations inherent to apparent metabolic and physiological differences between rodents and humans, or due to differences concerning adipose tissue biology ${ }^{(11,186)}$. On the other hand, when carrying out obesity studies with human subjects, it has to be considered that the use of human subjects is limited and the standardisation of the experimental conditions may be rather restricted. When using the pig as an animal model, possible obesitymicrobiota interactions can be assessed under more controlled conditions of feed intake compared with investigations using human subjects, thereby maintaining standardised experimental conditions. In addition to similarities of digestive function and nutritional requirements, the major contributor to fat mass is the subcutaneous adipose tissue in both pigs and humans ${ }^{(11)}$. In addition, fat cell size and body fat distribution are similar in both species $^{(11)}$ and the pig's propensity to sedentary behaviour and fattening is comparable with that of humans ${ }^{(187)}$. Nevertheless, it has to be considered that the major site of lipogenesis in the pig is the adipose tissue ${ }^{(188)}$, while in humans it occurs mainly in the liver ${ }^{(189)}$, and the rapid growth and mature size of modern swine breeds to obtain maximal performance have to be taken into account when comparing the two species ${ }^{(32)}$. Still, the present, rather lean pig breeds will respond to a low-protein or high-fat diet by depositing more fat ${ }^{(190)}$.

In this context, Guo et al. ${ }^{(2)}$ conducted a study with a Banna mini-pig inbred line, which shows pathological phenotypes of obesity and thinness. Lower numbers of Bacteriodetes in faecal samples were associated with normal rather than with obese pigs (Table 5$)^{(2)}$. These findings are in agreement with the results of a study with human participants, where obese subjects showed fewer numbers of Bacteroidetes and more Firmicutes compared with lean 
Table 5. Bacteria phyla in obese mice, humans and pigs compared with normal-weight individuals

\begin{tabular}{|c|c|c|c|c|}
\hline Species & Method & Obese microbiota & Comparison & Reference \\
\hline$O b / o b^{*}$ mice & $\begin{array}{l}\text { Caecal 16S rRNA gene fragment sequence } \\
\text { of } o b / o b \text { and lean wild-type mice }\end{array}$ & $\begin{array}{l}\text { Bacteroidetes } \\
\text { Firmicutes }\end{array}$ & $\downarrow$ & Ley et al. ${ }^{(3)}$ \\
\hline Germ-free and $o b / o b$ mice & $\begin{array}{l}\text { Sequenced metagenome of obese and } \\
\text { lean mice }\end{array}$ & $\begin{array}{l}\text { Bacteroidetes } \\
\text { Firmicutes }\end{array}$ & $\downarrow$ & Turnbaugh et al. ${ }^{(1)}$ \\
\hline Human adults & $\begin{array}{l}\text { Intestinal microbiota (qPCR) and } \\
\text { faecal SCFA of obese and lean subjects }\end{array}$ & $\begin{array}{l}\text { Bacteroidetes } \\
\text { Firmicutes } \\
\text { Higher amount } \\
\text { of SCFA in obese }\end{array}$ & $\uparrow$ & Schwiertz et al. ${ }^{(182)}$ \\
\hline Human adults (female twins) & $\begin{array}{l}\text { qPCR analysis of gut microbiota of } \\
\text { obese and lean adults }\end{array}$ & $\begin{array}{l}\text { Bacteroidetes } \\
\text { Firmicutes }\end{array}$ & $\downarrow$ & Turnbaugh et al. ${ }^{(184)}$ \\
\hline Pigs & $\begin{array}{l}\text { QPCR analysis of faeces of obese and lean } \\
\text { Banna mini-pigs }\end{array}$ & $\begin{array}{l}\text { Bacteroidetes } \\
\text { Firmicutes }\end{array}$ & $\begin{array}{l}\downarrow \text { (NS) } \\
\leftrightarrow\end{array}$ & Guo et al. ${ }^{(2)}$ \\
\hline
\end{tabular}

RRNA, ribosomal RNA; $\downarrow$, lower; $\uparrow$, higher; qPCR, quantitative PCR; $\leftrightarrow$, no difference.

* Genetically obese animals.

ones $^{(191)}$. In this study, an increased abundance of Bacteroidetes was correlated with loss of BW, both following consumption of a carbohydrate- or fat-restricted $\operatorname{diet}^{(191)}$. In a recent study with Ossabaw mini-pigs, the obese group, which was fed a high-energy diet, also showed a higher abundance of Firmicutes in the terminal ileum, and lower abundance of Bacteroidetes in the colon than lean Ossabaw mini-pigs ${ }^{(192)}$. In addition, obese Ossabaw mini-pigs had lower abundances of the genera Prevotella and Lactobacillus and a higher abundance of Clostridium spp. in colon digesta than the lean animals. However, when in the same study Göttingen minipigs rather than Ossabaw mini-pigs were used, opposite results were obtained concerning the ratio of Firmicutes to Bacteroidetes, with a higher abundance of Firmicutes in the lean group. According to the authors of the study, certain bacterial groups such as Firmicutes may flourish best under high-fat-diet conditions as observed in Ossabaw mini-pigs, while others like Bacteroides prosper under diet conditions such as overeating as observed in Göttingen mini-pigs ${ }^{(192)}$. Additionally to research on these main bacterial groups, the prevalence of faecal methanogens of lean-breed Landrace pigs in comparison with obesebreed Erhualian pigs was determined ${ }^{(193)}$. These authors found a higher density and diversity of methanogens in the faecal samples of the lean breed. Since the formation of methane has been associated with energy loss in ruminants ${ }^{(194)}$, a highly dense and diverse methanogen community may also indicate energy loss in singlestomached animals, thereby affecting energy metabolism and body fat mass formation ${ }^{(193)}$. Similarly, anorexic patients exhibited an even higher diversity of Methanobrevibacter smithii compared with lean subjects ${ }^{(195)}$. Moreover, He et $a l .{ }^{(196)}$ used genetically obese pigs (Ningxiang strain) as an animal model for childhood obesity, and compared them with lean (Duroc $\times$ Landrace $\times$ Large Yorkshire strain) growing pigs. Among other serum metabolites, they found reduced concentrations of trimethylamine- $N$-oxide, and increased concentrations of choline in the serum of obese compared with lean pigs.
These metabolites have eventually been associated with functions of the gut microbiota ${ }^{(197,198)}$, thus indicating a possible relationship between the development of obesity and modulated microbial nutrient metabolism. Earlier, Varel et $a l .{ }^{(199)}$ used genetically obese and lean pigs to study the effect of low or high dietary fibre content on cellulolytic bacteria numbers. According to the authors, the obese pigs showed a tendency for lower numbers of cellulolytic bacteria in faecal samples following consumption of the high-fibre diet compared with the lean pigs, probably due to the faster digesta passage rate observed in obese pigs. In conclusion, these studies confirm the potential of pigs to serve as a model animal for obesity research.

Dietary strategies as therapeutic tools for obesity. To possibly overcome obesity, different pre- and probiotics have been assessed for their potential to modulate gut bacteria associated with obesity ${ }^{(200,201)}$; however, until now mainly rodent models or human subjects have been used. Prebiotic components with a positive impact on obesity include oligofructose, which stimulated caecal bifidobacteria numbers in mice fed a high-fat diet and reduced the metabolic disease ${ }^{(202)}$. In a study with rats, An et al. ${ }^{(203)}$ found beneficial anti-obesity effects due to supplementation with the probiotic Bifidobacterium spp. to a highfat diet (Bifidobacterium pseudocatenulatum SPM 1204, Bifidobacterium longum SPM 1205, Bifidobacterium longum 1207), with reduced body and fat weights and blood serum levels (for example, TAG, glucose, leptin) and increased total faecal lactic acid bacteria counts in the probiotic-supplemented high-fat diet compared with the diet devoid of probiotics.

In young adults, dietary supplementation with oligofructose in combination with inulin caused a smaller increase in BMI and total fat mass ${ }^{(200)}$. As a probiotic strain, L. rhamnosus applied as a perinatal intervention diminished the initial phase of excessive weight gain in infants ${ }^{(204)}$, while L. gasseri in fermented milk significantly decreased visceral and subcutaneous fat areas as well as BW of overweight human participants ${ }^{(201)}$. Potential effects 
of these food additives on the gut microbiota composition were not determined in the aforementioned studies.

In addition to the application of food additives such as pro- and prebiotics, modulating diet composition has been shown to be effective as well, since a decrease in Firmicutes in faecal samples was observed for a high-protein/ low-carbohydrate diet conceived for weight loss in human subjects ${ }^{(7)}$. Conversely, an increase of Firmicutes was induced by a high-fat/high-sugar Western diet in mice $^{(205)}$. The use of a porcine model may have advantages due to the limitations of rodents and human subjects in disease research, because of the metabolic and physiological differences between humans and rodents ${ }^{(11,186)}$, and limitations of availability and standardisation of experimental conditions for human models. This is underlined by the inconsistencies observed amongst studies using rodents and human subjects, emphasising the need for a more reliable and standardised animal model, as could be provided by the pig. Thus, studies concerning food additives to be applied in humans have been tested in the pig as well. Accordingly, Wall et al. ${ }^{(206)}$ investigated the impact of orally administered Bifidobacterium breve in combination with linoleic acid in sunflower-seed oil on the fatty acid composition both of murine and porcine liver and adipose tissues. Here, analysis of pigs' faeces, and small- and large-intestinal contents confirmed the GI transit and survival of the administered Bifidobacterium strain. Furthermore, in porcine livers, following the supplementation of Bifidobacterium breve and linoleic acid, a 1.5-fold higher cis-9, trans-11-conjugated linoleic acid (CLA) content was found compared with unsupplemented control animals ${ }^{(206)}$. The addition of Bifidobacterium breve also led to an increase of cis-9, trans-11-CLA in the adipose tissue of these pigs, but the increase was not significantly different from that in the controls. These results are of therapeutic relevance, since CLA has been shown to improve non-alcoholic fatty liver disease, a condition accompanying obesity, in rats and human patients ${ }^{(206-208)}$. Thus, elevation of cis-9, trans-11-CLA in the liver as produced by Bifidobacterium breve in this trial might be a possibility for treating liver dysfunctions of that kind in humans ${ }^{(206)}$. In another study, Andersen et al. ${ }^{(21)}$ investigated the effects of dietary long-chain $n$-3 PUFA supplementation from fish oil to the diet of piglets. In contrast to similar studies with rodents ${ }^{(209,210)}$ and human subjects $^{(211,212)}$, these authors, as well as Kratz et al. ${ }^{(213)}$ in a study with human subjects, failed to obtain any effect on adipose tissue mass in the pig model ${ }^{(21)}$. Also, a correlation between the caecal content of Bacteroides spp. and fat mass as monitored before in human subjects, mice and pigs ${ }^{(2,3,191)}$ could not be determined ${ }^{(21)}$. However, the authors observed an influence of dietary PUFA on the overall bacterial community in the caecum, as shown for the faecal bacteria of human infants as well $^{(214)}$, and a degrading effect of $n-3$ PUFA on the Bacteroidetes community $^{(21)}$. Generally, the pig model seems to be promising in research concerning the assessment of dietary strategies to improve the obesity syndrome, due to the described advantages compared with rodents and human models.

Further options for the application of the pig as a model for research into microbiota-associated diseases

Another application area for the use of pigs as a model for microbiota-associated diseases is the pathogenesis of Helicobacter pylori infection, which is a major reason for the genesis of gastritis and peptic ulcers in humans ${ }^{(215,216)}$. The use of diverse animal models was reviewed by Kusters et $a l{ }^{(217)}$, who pointed out the advantages of the gnotobiotic piglet, as it is a single-stomached mammal with similar needs in nutrition, and has a stomach with similar anatomical and physiological characteristics compared with humans. Colonisation of gnotobiotic piglets with H. pylori results in gastritis and gastric ulcers, and with the porcine model, the importance of $H$. pylori urease activity and motility for colonisation, besides other virulence factors, could be proved. Furthermore, antimicrobial therapies and the application of vaccination have been tested with this model. However, despite these promising results about the use of pigs as a model for research in gastritis and gastric ulcers, nowadays, for unspecified reasons, the pig is no longer used as model for research in this field ${ }^{(217)}$.

\section{Possible improvement of the pig as an animal model: human flora-associated pigs}

Recently, research directed to the use of pigs as an animal model also included human flora-associated (HFA) animal models by transplantation of human gut microbiota into gnotobiotic animals, both in pigs and rodents ${ }^{(218-220)}$. However, in rodents, due to the apparent differences in anatomy and physiology compared with humans, some key members of the human gut microbiota such as bifidobacteria do not colonise the rodent gut. Therefore, according to Pang et al. $^{(220)}$, results based on the use of rodent models often appear to be hardly relevant for humans. On the contrary, Pang et al. ${ }^{(220)}$ successfully used the pig as a HFA animal model. Here, it has been observed that DNA fingerprints of HFA piglets were more similar to those of humans than to those of conventionally raised piglets. Moreover, with Bacteroides spp. and bifidobacteria, two important bacterial groups of the human gut were effectively established in the GIT of the pigs ${ }^{(211)}$. A significant increase in the amount of bifidobacteria spp. in HFA compared with pig flora-associated pigs has also been observed by Che et al. ${ }^{(221)}$. Accordingly, Shen et al. ${ }^{(22)}$ described the HFA piglet as 'a significantly improved model for research on human gut microbiota'. In their study, the modulating effects of prebiotic FOS on faecal microbiota have been assessed, as by confirming the bifidogenic properties of short-chain FOS $^{(222)}$. For that reason, 
HFA pigs might have the potential to mimic the human gut microbiota even more authentically, and thus may be used more frequently as an animal model in the future.

\section{Conclusions}

The pig has already been used in many studies as an animal model for humans to assess the gut microbiota, due to similarities in GIT functions and anatomical structure, metabolism and nutritional requirements, but also due to similar major bacteria phyla occurring in the GIT of pigs (Firmicutes, Bacteroidetes). However, considerable differences in bacterial composition have to be accounted for, which may at least in part be attributed to differences between pigs and humans, for example, relating to environmental aspects or characteristic behaviour.

With regard to research on dietary modulation of the intestinal microbiota as a therapeutic or preventive tool, a recent study confirmed the similarity of the pig to humans in view of genetic and protein malfunctions as accounting for obesity and other distinct symptoms such as diabetes ${ }^{(223)}$. Furthermore, the pig might serve as a suitable animal model for studying other diseases such as colon cancer. For example, dietary fibre may exhibit a protective effect against the development of colon cancer $^{(224)}$, since its consumption appears to be associated with a diluting effect on carcinogens due to an increased faecal bulk $^{(225)}$, as well as with the stimulation of butyrate production, an effective promoter of epithelial growth in the large intestine ${ }^{(22)}$. As dietary stimulation of intestinal butyrate production has also been shown in pigs ${ }^{(227)}$, it can be suggested that the pig as an model animal could be a useful option when investigating dietary strategies to beneficially affect microbial ecology for human health purposes. However, research is still needed to further scrutinise the efficient use of pigs in research directed to serve human needs. Within this regard, the use of HFA pigs should be considered to possibly improve the pig as a model for humans.

\section{Acknowledgements}

We thank Silke Hoerner for assisting in preparing the manuscript.

The present review received no specific grant from any funding agency in the public, commercial or not-for-profit sectors. S. N. H. is supported by a doctoral scholarship awarded by the Faculty of Agricultural Sciences of the University of Hohenheim. The Faculty of Agricultural Sciences of the University of Hohenheim had no role in the design, analysis or writing of this article.

R. M. and E. W. are responsible for the conceptualisation and implementation of the manuscript. S. N. H. wrote the manuscript. All authors reviewed the manuscript and approved submission.

There are no conflicts of interest.

\section{References}

1. Turnbaugh PJ, Ley RE, Mahowald MA, et al. (2006) An obesity-associated gut microbiome with increased capacity for energy harvest. Nature 444, 1027-1031.

2. Guo X, Xia X, Tang R, et al. (2008) Development of a real-time PCR method for Firmicutes and Bacteroidetes in faeces and its application to quantify intestinal population of obese and lean pigs. Lett Appl Microbiol $\mathbf{4 7}$, $367-373$.

3. Ley RE, Backhed F, Turnbaugh P, et al. (2005) Obesity alters gut microbial ecology. Proc Natl Acad Sci US A 102, 11070-11075.

4. Schwiertz A, Gruhl B, Löbnitz M, et al. (2003) Development of the intestinal bacterial composition in hospitalized preterm infants in comparison with breast-fed, full-term infants. Pediatr Res 54, 393-399.

5. Magne F, Hachelaf W, Suau A, et al. (2006) A longitudinal study of infant faecal microbiota during weaning. FEMS Microbiol Ecol 58, 563-571.

6. Govers MJAP, Gannon NJ, Dunshea FR, et al. (1999) Wheat bran affects the site of fermentation of resistant starch and luminal indexes related to colon cancer risk: a study in pigs. Gut 45, 840-847.

7. Duncan SH, Lobley GE, Holtrop G, et al. (2008) Human colonic microbiota associated with diet, obesity and weight loss. Int J Obes 32, 1720-1724.

8. Schrezenmeir J \& de Vrese M (2001) Probiotics, prebiotics, and synbiotics - approaching a definition. Am J Clin Nutr 73, 361S-364S.

9. Marik PE (2012) Colonic flora, probiotics, obesity and diabetes. Front Endocrin 3, 87.

10. Gibson GR \& Roberfroid MB (1995) Dietary modulation of the human colonic microbiota: introducing the concept of prebiotics. J Nutr 125, 1401-1412.

11. Houpt AK, Houpt R \& Pond WG (1979) The pig as a model for the study of obesity and of control of food intake: a review. Yale J Biol Med 52, 307-329.

12. Graham H \& Aman P (1987) The pig as a model in dietary fibre digestion studies. Scand J Gastroenterol 22, 55-61.

13. Van Soest PJ, Jeraci J, Fosse T, et al. (1982) Comparative fermentation of fibre in man and other animals. In Fibre in Human and Animal Nutrition, Bulletin no. 20, pp. 75-80 [G Wallace and L Bell, editors]. Wellington: The Royal Society of New Zealand.

14. Brooks SP, McAllister M, Sandoz M, et al. (2003) Cultureindependent phylogenetic analysis of the faecal flora of the rat. Can J Microbiol 49, 589-601.

15. Manichanh C, Reeder J, Gibert P, et al. (2010) Reshaping the gut microbiome with bacterial transplantation and antibiotic intake. Genome Res 20, 1411-1419.

16. Tomas J, Langella P \& Cherbuy C (2012) The intestinal microbiota in the rat model: major breakthroughs from new technologies. Anim Health Res Rev 13, 54-63.

17. Lay C, Rigottier-Gois L, Holmstrom K, et al. (2005) Colonic microbiota signatures across five northern European countries. Appl Environ Microbiol 71, 4153-4155.

18. Dalby AB, Frank DN, St Amand AL, et al. (2006) Cultureindependent analysis of indomethacin induced alterations in the rat gastrointestinal microbiota. Appl Environ Microbiol 72, 6707-6715.

19. Delroisse JM, Boulvin AL, Parmentier I, et al. (2008) Quantification of Bifidobacterium spp. and Lactobacillus spp. in rat fecal samples by real-time PCR. Res Microbiol 163 , 663-670.

20. Oli MW, Petschow BW \& Buddington RK (1998) Evaluation of fructooligosaccharide supplementation of oral electrolyte 
solutions for treatment of diarrhoea: recovery of the intestinal bacteria. Dig Dis Sci 43, 138-147.

21. Andersen AD, Mølbak L, Thymann T, et al. (2011) Dietary long-chain $n-3$ PUFA, gut microbiota and fatmass in early postnatal piglet development - exploring a potential interplay. Prostaglandins Leukot Essent Fatty Acids 85, $345-351$.

22. Leser TD, Amernuvor JZ \& Jensen TK (2002) Cultureindependent analysis of gut bacteria: the pig gastrointestinal tract microbiota revisited. Appl Environ Microbiol 68, 673-690.

23. Miller ER \& Ullrey DE (1987) The pig as a model for human nutrition. Annu Rev Nutr 7, 361-382.

24. Baker DH (2008) Animal models in nutrition research. J Nutr 138, 391-396.

25. Puiman P \& Stoll B (2008) Animal models to study neonatal nutrition in humans. Curr Opin Clin Nutr Metab Care 11, 601-606.

26. Kien CL, Ailabouni AH, Murray RD, et al. (1997) Technical note: pig model for studying nutrient assimilation by the intestine and colon. J Anim Sci 75, 2161-2164.

27. Labib S, Erb A, Kraus M, et al. (2004) The pig caecum model: a suitable tool to study the intestinal metabolism of flavonoids. Mol Nutr Food Res 48, 326-332.

28. Emmans GC \& Kyriazakis I (1999) Growth and body composition. In A Quantitative Biology of the Pig, pp. 181-198 [I Kyriazakis, editor]. Wallingford: CAB International.

29. Mochizuki S \& Makita T (1998) Differences in intestinal length between specific-pathogen-free (SPF) and conventional swine. I Vet Med Sci 60, 545-548.

30. Van Rens BTTM \& Van Der Lende T (2002) Litter size and piglet traits of gilts with different prolactin receptor genotypes. Theriogenology 57, 883-893.

31. Patterson JK, Lei XG \& Miller DD (2008) The pig as an experimental model for elucidating the mechanisms governing dietary influence on mineral absorption. Exp Biol Med 233, 651-664.

32. Rispat G, Slaoui M, Weber D, et al. (1993) Haematological and plasma biochemical values for healthy Yucatan micropigs. Lab Anim Sci 27, 368-373.

33. Guilloteau P, Zabielski R, Hammon HM, et al. (2010) Nutritional programming of gastrointestinal tract development. Is the pig a good model for man? Nutr Res Rev $\mathbf{2 3}$, $4-22$.

34. Ehle FR, Jeraci JL, Robertson JB, et al. (1982) The influence of dietary fiber on digestibility, rate of passage and gastrointestinal fermentation in pigs. J Anim Sci 55, 1071-1081.

35. Rérat A, Fiszlewicz M, Giusi A, et al. (1987) Influence of meal frequency on postprandial variations in the production and absorption of volatile fatty acids in the digestive tract of conscious pigs. Anim Sci 64, 448-456.

36. Argenzio RA \& Stevens CE (1984) The large intestine bowel - a supplementary rumen. Proc Nutr Soc 43, 13-23.

37. von Engelhardt W, Bartels J, Kirschberger S, et al. (1998) Role of short-chain fatty acids in the hind gut. Vet $Q \mathbf{2 0}$, $52-59$.

38. Allison C \& Macfarlane $\mathrm{T}$ (1989) Influence of $\mathrm{pH}$, nutrient availability and growth rate on amine production by Bacteroides fragilis and Clostridium perfringens. Appl Environ Microbiol 55, 2894-2898.

39. Cummings JH \& Englyst HN (1987) Fermentation in the human large intestine and the available substrates. $\mathrm{Am} \mathrm{J}$ Clin Nutr 4, 1243-1255.

40. Louis P, Scott KP, Duncan SH, et al. (2007) Understanding the effects of diet on bacterial metabolism in the large intestine. J Appl Microbiol 102, 1197-1208.
41. Wright RS, Anderson JW \& Bridges SR (1990) Propionate inhibits hepatocyte lipid synthesis. Exp Biol Med 195, 26-29.

42. Vogt JA, Pencharz PB \& Wolever TMS (2004) L-Rhamnose increases serum propionate in humans. Am J Clin Nutr 80, 89-94.

43. Pryde SE, Duncan SH, Hold GL, et al. (2002) The microbiology of butyrate formation in the human colon. FEMS Microbiol Lett 17, 133-139.

44. Aminov RI, Walker AW, Duncan SH, et al. (2006) Molecular diversity, cultivation, and improved detection by fluorescent in situ hybridization of a dominant group of human gut bacteria related to Roseburia spp. or Eubacterium rectale. Appl Anim Ethol 72, 6371-6376.

45. Asahara T, Shimizu K, Nomoto K, et al. (2001) Antibacterial effect of fermented milk containing Bifidobacterium breve, Bifidobacterium bifidum and Lactobacillus acidophilus against indigenous Escherichia coli infection in mice. Microb Ecol Health Dis 13, 16-24.

46. Zoetendal EG, Akkermans ADL \& de Vos WM (1998) Temperature gradient gel electrophoresis analysis of 16S rRNA from human fecal samples reveals stable and host-specific communities of active bacteria. Appl Environ Microbiol 64, 3854-3859.

47. Zoetendal EG, von Wright A, Vilpponen-Salmela T, et al. (2002) Mucosa-associated bacteria in the human gastrointestinal tract are uniformly distributed along the colon and differ from the community recovered from feces. Appl Environ Microbiol 68, 3401-3407.

48. Zoetendal EG, Vaughan EE \& de Vos WM (2006) A microbial world within us. Mol Microbiol 6, 1639-1650.

49. Zoetendal EG, Rajilic-Stojanovic M \& de Vos WM (2008) High throughput diversity and functionality analysis of the gastrointestinal tract microbiota. Gut 57, 1605-1615.

50. Sghir A, Gramet G, Suau A, et al. (2000) Quantification of bacterial groups within human fecal flora by oligonucleotide probe hybridization. Appl Environ Microbiol 6, 2263-2266.

51. Doré J \& Corthier G (2010) The human intestinal microbiota. Gastroenterol Clin Biol 34, S7-S15.

52. Harmsen HJ, Raangs GC, He T, et al. (2002) Extensive set of $16 \mathrm{~S}$ rRNA-based probes for detection of bacteria in human feces. Appl Environ Microbiol 6, 2982-2990.

53. Rigottier-Gois L, Bourhis AG, Gramet G, et al. (2003) Fluorescent hybridisation combined with flow cytometry and hybridisation of total RNA to analyse the composition of microbial communities in human faeces using 16S rRNA probes. FEMS Microbiol Ecol 43, 237-245.

54. Flint HJ, Duncan SH, Scott KP, et al. (2007) Interactions and competition within the microbial community of the human colon: links between diet and health. Environ Microbiol 9, $1101-1111$.

55. Playne M (1994) Probiotic foods. Food Aust 46, 362-364.

56. Lay C, Sutren M, Rochet V, et al. (2005) Design and validation of $16 \mathrm{~S}$ rRNA probes to enumerate members of the Clostridium leptum subgroup in human faecal microbiota. Environ Microbiol 7, 933-946.

57. Mueller S, Saunier K, Hanisch C, et al. (2006) Differences in fecal microbiota in different European study populations in relation to age, gender, and country: a cross-sectional study. Appl Environ Microbiol 72, 1027-1033.

58. Reuter G (2001) The Lactobacillus and Bifidobacterium microflora of the human intestine: composition and succession. Curr Issues Intest Microbiol 2, 43-53.

59. Fallani M, Young D, Scott J, et al. (2010) The intestinal microbiota of 6-week-old infants across Europe: geographic influence beyond delivery mode, breastfeeding and antibiotics. J Pediatr Gastroenterol Nutr 51, 77-84. 
60. Moore WEC, Moore LVH, Cato EP, et al. (1987) Effect of high-fiber and high-oil diets on the fecal flora of swine. Appl Environ Microbiol 53, 1638-1644.

61. Stewart CS (1997) Microorganisms in hindgut fermentors. In Gastrointestinal Microbiology, vol. 2, pp. 142-186 [RI Mackie, BA White and RE Isaacson, editors]. New York: Chapman and Hall.

62. Gaskins HR (2001) Intestinal bacteria and their influence on swine growth. In Swine Nutrition, pp. 585-608 [AJ Lewis and LL Southern, editors]. Boca Raton: CRC Press.

63. Jensen BB (2001) Possible ways of modifying type and amount of products from microbial fermentation in the gut. In Gut Environment of Pigs, pp. 181-200 [A Piva, KE Bach Knudsen and JE Lindberg, editors]. Nottingham: Nottingham University Press.

64. van der Klis JD \& Jansman AJM (2002) Optimising nutrient digestion, absorption and gut barrier function in monogastrics: reality or illusion? In Nutrition and Health of the Gastrointestinal Tract, pp. 15-36 [MC Blok, HA Vahl, L de Lange, AE van de Braak, G Hemke and M Hessing, editors]. Wageningen: Wageningen Academic Publishers.

65. Hopwood DE \& Hampson DJ (2003) Interactions between the intestinal microflora, diet and diarrhoea, and their influences on piglet health in the immediate postweaning period. In Weaning the Pig: Concepts and Consequences, pp. 199-218 [JR Pluske, J Le Dividich and MWA Verstegen, editors]. Wageningen: Wageningen Academic Publishers.

66. Kim HB, Borewicz K, White BA, et al. (2011) Longitudinal investigation of the age-related bacterial diversity in the feces of commercial pigs. Vet Microbiol 153, 124-133.

67. Petri D, Hill JE \& Van Kessel AG (2010) Microbial succession in the gastrointestinal tract (GIT) of the preweaned pig. Livest Sci 133, 107-109.

68. Pieper R, Janczyk P, Zeyner A, et al. (2008) Ecophysiology of the total and Lactobacillus communities in the terminal small intestine of weaning piglets. Microb Ecol 56, 474-483.

69. Loh G, Eberhard M, Brunner RM, et al. (2006) Inulin alters the intestinal microbiota and short-chain fatty acid concentrations in growing pigs regardless of their basal diet. $J$ Nutr 136, 1198-1202.

70. Mikkelsen LL, Bendixen C, Jakobsen M, et al. (2003) Enumeration of bifidobacteria in gastrointestinal samples from piglets. Appl Environ Microbiol 69, 654-658.

71. Simpson PJ, Stanton C, Fitzgerald GF, et al. (2003) Genomic diversity and relatedness of bifidobacteria isolated from a porcine cecum. J Bacteriol 185, 2571-2581.

72. Krause DO, Easter RA, White BA, et al. (1995) Effect of weaning diet on the ecology of adherent lactobacilli in the gastrointestinal tract of the pig. J Anim Sci 73, $2347-2354$.

73. Leser TD, Lindecrona RH, Jensen TK, et al. (2000) Changes in bacterial community structure in the colon of pigs fed different experimental diets and after infection with $\mathrm{Bra}$ chyspira hyodysenteriae. Appl Environ Microbiol 66, 3290-3296.

74. Mariat D, Firmesse O, Levenez F, et al. (2009) The Firmicutes/Bacteroidetes ratio of the human microbiota changes with age. BMC Microbiol 9, 123.

75. Hooper LV, Littman DR \& Macpherson AJ (2012) Interactions between the microbiota and the immune system. Science 336, 1268-1273.

76. Bezirtzoglou E (1997) The intestinal microflora during the first weeks of life. Anaerobe 3, 173-177.

77. Gronlund MM, Lehtonen OP, Eerola E, et al. (1999) Fecal microflora in healthy infants born by different methods of delivery: permanent changes in intestinal flora after cesarean delivery. J Pediatr Gastroenterol Nutr 28, 19-25.

78. Penders J, Thijs C, Vink C, et al. (2006) Factors influencing the composition of the intestinal microbiota in early infancy. Pediatrics 118, 511-521.

79. Susick EK, Putnam M, Bermudez DM, et al. (2012) Longitudinal study comparing the dynamics of Clostridium difficile in conventional and antimicrobial free pigs at farm and slaughter. Vet Microbiol 157, 172-178.

80. Heavey PM \& Rowland IR (1999) The gut microbiology of the developing infant: microbiology and metabolism. Microbiol Ecol Health Dis 11, 75-83.

81. Yoshioka H, Iseki K \& Fujita K (1983) Development and differences of intestinal flora in the neonatal period in breast-fed and bottle-fed infants. Pediatrics 72, 317-321.

82. Kunz C \& Rudloff S (1993) Biological functions of oligosaccharides in human milk. Acta Paediatr 82, 903-912.

83. Newburg DS (1999) Human milk glycoconjugates that inhibit pathogens. Curr Med Chem 6, 117-127.

84. Langendijk PS, Schut F, Jansen GJ, et al. (1995) Quantitative fluorescence in situ hybridisation of Bifidobacterium spp. with genus-specific $16 \mathrm{~S}$ rRNA-targeted probes and its application in fecal samples. Appl Environ Microbiol 61, 3069-3075.

85. Heikkilä MP \& Saris PEJ (2003) Inhibition of Staphylococcus aureus by the commensal bacteria of human milk. $J$ Appl Microbiol 95, 471-478.

86. West PA, Hewitt JH \& Murphy OM (1979) Influence of methods of collection and storage on the bacteriology of human milk. J Appl Microbiol 46, 269-277.

87. Kirjavainen PV, Apostolou E, Arvola T, et al. (2001) Characterizing the composition of intestinal microflora as a prospective treatment target in infant allergic disease. FEMS Immunol Med Microbiol 32, 1-7.

88. Favier C, Vaughan EE, De Vos WM, et al. (2002) Molecular monitoring of succession of bacterial communities in human neonates. Appl Environ Microbiol 68, 219-226.

89. Pieper R, Janczyk P, Schumann R, et al. (2006) The intestinal microflora of piglets around weaning with emphasis on lactobacilli. Arch Zootech 9, 28-40.

90. Montagne L, Arturo-Schaan M, Le Floc'h N, et al. (2010) Effect of sanitary conditions and dietary fibre on the adaptation of gut microbiota after weaning. Livest Sci 133, 113-116.

91. Thangaraju M, Cresci GA, Liu K, et al. (2009) GPR109A is a G-proteincoupled receptor for the bacterial fermentation product butyrate and functions as a tumor suppressor in colon. Cancer Res 69, 2826-2832.

92. Duncan SH, Louis P \& Flint HJ (2004) Lactate-utilizing bacteria, isolated from human feces, that produce butyrate as a major fermentation product. Appl Environ Microbiol $\mathbf{7 0}$ 5810-5817.

93. Watson TS \& Bertram JM (1983) Some observations on mother-infant interactions in the pig (Sus scrofa). Appl Anim Ethol 9, 253.

94. Gleed PT \& Sansom BF (1982) Ingestion of iron in sow's feces by piglets reared in farrowing crates with slatted floors. Br J Nutr 47, 113-117.

95. Schmidt B, Mulder IE, Musk CC, et al. (2011) Establishment of normal gut microbiota is compromised under excessive hygiene conditions. PLOS ONE 6, e28284.

96. Lunney JK (2007) Advances in swine biomedical model genomics. Int J Biol Sci 3, 179-184.

97. Lamendella R, Domingo JW, Ghosh S, et al. (2011) Comparative fecal metagenomics unveils unique functional capacity of the swine gut. BMC Microbiol 11, 103.

98. Nabuurs MJA (1998) Weaning piglets as a model for studying pathophysiology of diarrhoea. Vet $Q \mathbf{2 0}, 42-45$. 
99. Fujiwara S, Hashiba H, Hirota T, et al. (1997) Proteinaceous factor(s) in culture supernatant fluids of bifidobacteria which prevents the binding of enterotoxigenic Escherichia coli to gangliotetraosylceramide. Appl Environ Microbiol 63, 506-512.

100. Gordon JE, Chitkara ID \& Wyon JB (1963) Weanling diarrhoea. Am J Med Sci 245, 129-160.

101. Nabuurs MJA, van Zijderveld FG \& de Leeuw PW (1993) Clinical and microbiological field studies in the Netherlands of diarrhoea in pigs at weaning. Res Vet Sci $\mathbf{5 5}$, 70-77.

102. Nataro JP \& Kaper JB (1998) Diarrhoeagenic Escherichia coli. Clin Microbiol Rev 11, 142-201.

103. Gaastra W \& de Graaf FK (1982) Host-specific fimbrial adhesions of noninvasive enterotoxigenic Escherichia coli strains. Microbiol Rev 46, 129-161.

104. de Zoysa I, Rea M \& Martines J (1991) Why promote breastfeeding in diarrhoeal disease control programmes? Health Policy Plan 6, 371-379.

105. Newburg DS (2005) Innate immunity and human milk. J Nutr 135, 1308-1312.

106. Lara-Villoslada F, Olivares M, Sierra S, et al. (2007) Beneficial effects of probiotic bacteria isolated from breast milk. Br J Nutr 98, Suppl. 1, S96-S100.

107. Wagstrom EA, Yoon KJ \& Zimmerman JJ (2000) Immune components in porcine mammary secretions. Viral Immunol 13, 383-397.

108. Martín R, Delgado S, Maldonado A, et al. (2009) Isolation of lactobacilli from sow milk and evaluation of their probiotic potential. J Dairy Res 76, 418-425.

109. Cummins AG, Steele TW, LaBrooy JT, et al. (1988) Maturation of the rat small intestine at weaning: changes in epithelial cell kinetics, bacterial flora, and mucosal immune activity. Gut 29, 1672-1679.

110. Pluske JR, Hampson DJ \& Williams IH (1997) Factors influencing the structure and function of the small intestine in the weaned pig: a review. Livest Prod Sci 51, 215-236.

111. Lecce JG, Clare DA, Balsbaugh RK, et al. (1983) Effect of dietary regimen on rotavirus-Escherichia coli weanling diarrhoea of piglets. J Clin Microbiol 17, 689-695.

112. Parashar UD, Bresee JS, Gentsch JR, et al. (1998) Rotavirus. Emerg Infect Dis 4, 561-570.

113. Parashar UD, Gibson C, Bresee JS, et al. (2006) Rotavirus and severe childhood diarrhoea. Emerg Infect Dis 12, 304-306.

114. Ramig RF (2004) Pathogenesis of intestinal and systemic rotavirus infection. J Virol 78, 10213-10220.

115. Shu Q, Freeman Q \& Harsharnjit SG (2001) Probiotic treatment using Bifidobacterium lactis HN019 reduces weanling diarrhoea associated with rotavirus and Escherichia coli infection in a piglet model. J Pediatr Gastroenterol Nutr 33, 171-177.

116. Gill HS \& Guarner F (2004) Probiotics and human health: a clinical perspective. Postgrad Med J 80, 516-526.

117. Lallès JP, Bosi P, Smidt H, et al. (2007) Nutritional management of gut health in pigs around weaning. Proc Nutr Soc 66, 260-268.

118. Szajewska H \& Mrukowicz JZ (2001) Probiotics in the treatment and prevention of acute infectious diarrhoea in infants and children: a systematic review of published randomized, double-blind, placebo-controlled trials. $J$ Pediatr Gastroenterol Nutr 33, S17-S25.

119. Gill HS, Rutherford KJ, Prasad J, et al. (2000) Enhancement of natural and acquired immunity by Lactobacillus rhamnosus (HN001), Lactobacillus acidophilus (HN017) and Bifidobacterium lactis (HN019). Br J Nutr 83, 167-176.
120. Arunachalam K, Gill HS \& Chandra RK (2000) Enhancement of natural immune function by dietary consumption of Bifidobacterium lactis (HN019). Eur J Clin Nutr 54, 263-267.

121. Schroeder B, Duncker S, Barth S, et al. (2006) Preventive effects of the probiotic Escherichia coli strain Nissle 1917 on acute secretory diarrhoea in a pig model of intestinal infection. Dig Dis Sci 51, 724-731.

122. Eisenberg PG (1993) Causes of diarrhea in tube-fed patients: a comprehensive approach to diagnosis and management. Nutr Clin Pract 8, 119-123.

123. Brown DR, Overend MF \& Treder BG (1990) Neurohormonal regulation of ion transport in the porcine distal jejunum. Actions of somatostatin-14 and its natural and synthetic homologs. J Pharmacol Exp Ther 252, 126-134.

124. Eto B, Boisset M \& Desjeux JF (1996) Sodium fluoride inhibits the antisecretory effect of peptide YY and its analog in rabbit jejunum. Arch Physiol Biochem 104, 180-184.

125. Cermak R, Follmer U \& Wolffram S (1998) Dietary flavonol quercetin induces chloride secretion in rat colon. Am J Physiol 275, G1166-G1172.

126. Patterson JK, Yasuda K, Welch RM, et al. (2010) Supplemental dietary inulin of variable chain lengths alters intestinal bacterial populations in young pigs. $J$ Nutr 140, 2158-2161.

127. Buddington RK, Williams CH, Chen S, et al. (1996) A dietary supplement of neosugar alters the fecal flora and decrease $\mathrm{s}$ activities of some reductive enzymes in human subjects. $\mathrm{Am}$ J Clin Nutr 63, 709-716.

128. Donovan SM, Wang M, Li M, et al. (2012) Host-microbe interactions in the neonatal intestine: role of human milk oligosaccharides. Adv Nutr 3, 450S-455S.

129. Herfel TM, Jacobi SK, Lin X, et al. (2011) Polydextrose enrichment of infant formula demonstrates prebiotic characteristics by altering intestinal microbiota, organic acid concentrations, and cytokine expression in suckling piglets. J Nutr 141, 2139-2145.

130. Herfel TM, Jacobi SK, Lin X, et al. (2009) Safety evaluation of polydextrose in infant formula using a suckling piglet model. Food Chem Toxicol 47, 1530-1537.

131. Kien CL, Chang JC, Cooper JR, et al. (2004) Effects of prefeeding a prebiotic on diarrhoea and colonic cell proliferation in piglets fed lactulose. J Parenter Enteral Nutr 28, $22-26$.

132. Kien CL, Murray RD, Qualman SJ, et al. (1999) Lactulose feeding in piglets: a model for persistent diarrhoea and colitis induced by severe sugar malabsorption. Dig Dis Sci $\mathbf{4 4}$, 1476-1484.

133. Flourie B, Briet F, Florent C, et al. (1993) Can diarrhoea induced by lactulose be reduced by prolonged ingestion of lactulose? Am J Clin Nutr 58, 369-375.

134. Torrallardona D, Conde MR, Badiola I, et al. (2003) Effect of fishmeal replacement with spray-dried animal plasma and colistin on intestinal structure, intestinal microbiology, and performance of weanling pigs challenged with Escherichia coli K99. J Anim Sci 81, 1220-1226.

135. Toda M, Okubo S, Ikagai H, et al. (1992) The protective activity of tea catechins against experimental-infection by Vibrio cholerae. Microbiol Immunol 36, 999-1001.

136. Ishihara N, Chu DC, Akachi S, et al. (2001) Improvement of intestinal microflora balance and prevention of digestive and respiratory organ diseases in calves by green tea extracts. Livest Prod Sci 68, 217-229.

137. Bruins MJ, Cermak R, Kiers JL, et al. (2006) In vivo and in vitro effects of tea extracts on enterotoxigenic Escherichia coli-induced intestinal fluid loss in animal models. J Pediatr Gastroenterol Nutr 43, 459-469. 
138. Terada A, Hara H, Nakajyo S, et al. (1993) Effect of supplements of tea polyphenols on the cecal flora and cecal metabolites of chicks. Microb Ecol Health Dis 6, 3-9.

139. Hara H, Orita N, Hatano S, et al. (1995) Effect of tea polyphenols on fecal flora and fecal metabolic products of pigs. $J$ Vet Med Sci 57, 45-49.

140. Ishihara N \& Akachi S (1997) Green tea extract as a remedy for diarrhoea in farm-raised calves. In Chemistry and Applications of Green Tea, pp. 137-144 [T Yamamoto, LR Juneja, DC Chu and M Kim, editors]. Boca Raton: CRC Press LLC.

141. Hara Y (1997) Influence of tea catechins on the digestive tract. J Cell Biochem Suppl 27, 52-58.

142. Friedman M (2007) Overview of antibacterial, antitoxin, antiviral, and antifungal activities of tea flavonoids and teas. Mol Nutr Food Res 51, 116-134.

143. Neilands JB (1995) Siderophores - structure and function of microbial iron transport compounds. J Biol Chem 270, 26723-26726.

144. Bruins MJ, Vente-Spreeuwenberg MAM, Smits $\mathrm{CH}$, et al. (2011) Black tea reduces diarrhoea prevalence but decreases growth performance in enterotoxigenic Escherichia coli-infected post-weaning piglets. Anim Physiol Anim Nutr 95, 388-398.

145. Ngure FM, Wanyoko JK, Mahungu SM, et al. (2009) Catechins depletion patterns in relation to theaflavin and thearubigins formation. Food Chem 115, 8-14.

146. Neu J \& Weiss MD (1999) Necrotizing enterocolitis: pathophysiology and prevention. J Parenter Enteral Nutr 23, S13-S17.

147. Sangild PT (2006) Gut responses to enteral nutrition in preterm infants and animals. Exp Biol Med (Maywood) 231, 1695-1711.

148. Neu J (1996) Necrotizing enterocolitis - the search for a unifying pathogenic theory leading to prevention. Pediatr Clin North Am 43, 409-432.

149. Travadi JN, Patole SK \& Simmer K (2003) Gastric pneumatosis in neonates: revisited. I Paediatr Child Health 39, $560-562$.

150. Lee JS \& Polin RA (2003) Treatment and prevention of necrotizing enterocolitis. Semin Neonatol 8, 449-459.

151. Siggers RH, Siggers J, Thymann T, et al. (2011) Nutritional modulation of the gut microbiota and immune system in preterm neonates susceptible to necrotizing enterocolitis. J Nutr Biochem 22, 511-521.

152. Hoy CM, Wood CM, Hawkey PM, et al. (2000) Duodenal microflora in very-low-birth-weight neonates and relation to necrotizing enterocolitis. J Clin Microbiol 38, 4539-4547.

153. de la Cochetiere MF, Piloquet H, des Robert C, et al. (2004) Early intestinal bacterial colonization and necrotizing enterocolitis in premature infants: the putative role of Clostridium. Pediatr Res 56, 366-370.

154. Jiang P, Sangild PT, Siggers RH, et al. (2010) Bacterial colonization affects the intestinal proteome of preterm pigs susceptible to necrotizing enterocolitis. Neonatology 99, 280-288.

155. Cilieborg MS, Boye M, Molbak L, et al. (2011) Preterm birth and necrotizing enterocolitis alter gut colonization in pigs. Pediatr Res 69, 10-16.

156. Sangild PT, Siggers RH, Schmidt M, et al. (2006) Diet and colonization-dependent intestinal dysfunction predisposes to necrotizing enterocolitis in preterm pigs. Gastroenterology 130, 1776-1792.

157. Darragh AJ \& Moughan PJ (1995) The three-week-old piglet as a model animal for studying protein digestion in human infants. J Pediatr Gastroenterol Nutr 21, 387-393.
158. Bjornvad CR, Thymann T, Deutz NE, et al. (2008) Enteral feeding induces diet-dependent mucosal dysfunction, bacterial proliferation, and necrotizing enterocolitis in preterm pigs on parenteral nutrition. Am J Physiol Gastrointest Liver Physiol 295, G1092-G1103.

159. Siggers RH, Siggers J, Boye M, et al. (2008) Early administration of probiotics alters bacterial colonization and limits diet-induced gut dysfunction and severity of necrotizing enterocolitis in preterm pigs. $J$ Nutr $\mathbf{1 3 8}$, 1437-1444

160. Braegger CHP (2009) Probiotika bei Früh- und Neugeborenen (Probiotics in premature and newborn). In Probiotika, Präbiotika und Synbiotika (Probiotics, Prebiotics and Synbiotics), pp. 283-288 [SC Bischoff, editor]. Stuttgart: Georg Thieme Verlag KG.

161. Westerbeek EAM, van den Berg A \& Lafeber HN (2006) The intestinal bacterial colonisation in preterm infants: a review of the literature. Clin Nutr 25, 361-368.

162. Claud EC \& Walker WA (2001) Hypothesis: inappropriate colonization of the premature intestine can cause neonatal necrotizing enterocolitis. FASEB J 15, 1398-1403.

163. Lin J (2004) Too much short chain fatty acids cause neonatal necrotizing enterocolitis. Med Hypotheses 62, 291-293.

164. Peng LY, He ZJ, Chen W, et al. (2007) Effects of butyrate on intestinal barrier function in a Caco-2 cell monolayer model of intestinal barrier. Pediatr Res 61, 37-41.

165. Dierick NA, Decuypere JA, Molly K, et al. (2002) The combined use of triacylglycerols containing medium-chain fatty acids (MCFAs) and exogenous lipolytic enzymes as an alternative for nutritional antibiotics in piglet nutrition I. In vitro screening of the release of MCFAs from selected fat sources by selected exogenous lipolytic enzymes under simulated pig gastric conditions and their effects on the gut flora of piglets. Livest Prod Sci 75, 129-142.

166. Zentek J, Buchheit-Renko S, Manner K, et al. (2012) Intestinal concentrations of free and encapsulated dietary medium-chain fatty acids and effects on gastric microbial ecology and bacterial metabolic products in the digestive tract of piglets. Arch Anim Nutr 66, 14-26.

167. Clark DA, Thompson JE, Weiner LB, et al. (1985) Necrotizing enterocolitis: intraluminal biochemistry in human neonates and a rabbit model. Pediatr Res 19, 919-921.

168. Lin J, Nafday SM, Chauvin SN, et al. (2002) Variable effects of short chain fatty acids and lactic acid in inducing intestinal mucosal injury in newborn rats. J Pediatr Gastroenterol Nutr 35, 545-550.

169. Pender SF, Quinn JJ \& Sanderson IR (2000) Butyrate upregulates stromelysin-1 production by intestinal mesenchymal cells. Am J Physiol Gastrointest Liver Physiol 279, G918-G924.

170. Butel MJ, Roland N, Hibert A, et al. (1998) Clostridial pathogenicity in experimental necrotising enterocolitis in gnotobiotic quails and protective role of bifidobacteria. J Med Microbiol 47, 391-399.

171. Bin-Nun A, Bromiker R, Wilschanski M, et al. (2005) Oral probiotics prevent necrotizing enterocolitis in very low birth weight neonates. J Pediatr 147, 192-196.

172. Lin HC, Su BH, Chen AC, et al. (2005) Oral probiotics reduce the incidence and severity of necrotizing enterocolitis in very low birth weight infants. Pediatrics 115, $1-4$.

173. Hoyos AB (1999) Reduced incidence of necrotizing enterocolitis associated with enteral administration of Lactobacillus acidophilus and Bifidobacterium infantis to neonates in an intensive care unit. Int J Infect Dis 3, 197-202. 
174. Cilieborg MS, Thymann T, Siggers R, et al. (2011) The incidence of necrotizing enterocolitis is increased following probiotic administration to preterm pigs. $J$ Nutr $\mathbf{1 4}$, 223-230.

175. Land MH, Rouster-Stevens K, Woods CR, et al. (2005) Lactobacillus sepsis associated with probiotic therapy. Pediatrics 115, 178-181.

176. Ohishi A, Takahashi S, Ito Y, et al. (2010) Bifidobacterium septicemia associated with postoperative probiotic therapy in a neonate with omphalocele. J Pediatr 156, 679-681.

177. Wagner RD, Warner T, Roberts L, et al. (1997) Colonization of congenitally immunodeficient mice with probiotic bacteria. Infect Immun 65, 3345-3351.

178. Cilieborg MS, Boye M \& Sangild PT (2012) Bacterial colonization and gut development in preterm neonates. Early Hum Dev 88, S41-S49.

179. World Health Organization (2012) Obesity and overweight: key facts http://www.who.int/mediacentre/factsheets/ fs311/en/index.html (accessed January 2013)

180. Fleissner CK, Huebel N, Abd El-Bary MM, et al. (2010) Absence of intestinal microbiota does not protect mice from diet-induced obesity. Br J Nutr 104, 919-929.

181. Greiner T \& Bäckhed F (2011) Effects of the gut microbiota on obesity and glucose homeostasis. Trends Endocrinol Metab 22, 117-123.

182. Schwiertz A, Taras D, Schafer K, et al. (2010) Microbiota and SCFA in lean and overweight healthy subjects. Obesity 18, 190-195.

183. Nadal I, Santacruz A, Marcos A, et al. (2009) Shifts in clostridia, Bacteroides and immunoglobulin-coating fecal bacteria associated with weight loss in obese adolescents. Int J Obes (Lond) 33, 758-767.

184. Turnbaugh PJ, Hamady M, Yatsunenko T, et al. (2009) A core gut microbiome in obese and lean twins. Nature 457, 480-484.

185. Kalliomäki M, Collado MC, Salminen S, et al. (2008) Early differences in fecal microbiota composition in children may predict overweight. Am J Clin Nutr 87, 534-538.

186. Arner P (2005) Resistin: yet another adipokine tells us that men are not mice. Diabetologia 48, 2203-2205.

187. Torres-Rovira L, Astiz S, Caro A, et al. (2012) Diet-induced swine model with obesity/leptin resistance for the study of metabolic syndrome and type 2 diabetes. Scientific World Journal 2012, 510149.

188. O'Hea EK \& Leveille GA (1969) Significance of adipose tissue and liver as sites of fatty acid synthesis in the pig and the efficiency of utilization of various substrates for lipogenesis. J Nutr 99, 338-344.

189. Letexier D, Pinteur C, Large V, et al. (2003) Comparison of the expression and activity of the lipogenic pathway in human and rat adipose tissue. J Lipid Res 44, 2127-2134.

190. Mitchell AD (2007) Impact of research with cattle, pigs, and sheep on nutritional concepts: body composition and growth. J Nutr 137, 711-714.

191. Ley RE, Turnbaugh PJ, Klein S, et al. (2006) Microbial ecology: human gut microbes associated with obesity. Nature 444, 1022-1023.

192. Pedersen R, Ingerslev HC, Sturek M, et al. (2013) Characterisation of gut microbiota in Ossabaw and Göttingen minipigs as models of obesity and metabolic syndrome. PLOS ONE 8, e56612.

193. Luo Y, Su Y, Wright ADG, et al. (2012) Lean breed Landrace pigs harbor fecal methanogens at higher diversity and density than obese breed Erhualian pigs. Archaea 2012, 605289.

194. Johnson KA \& Johnson DE (1995) Methane emissions from cattle. J Anim Sci 73, 2483-2492.
195. Armougom F, Henry M \& Vialettes B (2009) Monitoring bacterial community of human gut microbiota reveals an increase in Lactobacillus in obese patients and methanogens in anorexic patients. PLOS ONE 4, e7125.

196. He Q, Ren P \& Kong X (2012) Comparison of serum metabolite compositions between obese and lean growing pigs using an NMR-based metabonomic approach. J Nutr Biochem 23, 133-139.

197. Rezzi S, Ramadan Z, Fay LB, et al. (2007) Nutritional metabonomics: applications and perspectives. J Proteome Res $\mathbf{6}$, 513-525.

198. Li M, Wang B, Zhang M, et al. (2008) Symbiotic gut microbes modulate human metabolic phenotypes. Proc Natl Acad Sci U S A 105, 2117-2122.

199. Varel VH, Pond WG, Pekas JC, et al. (1982) Influence of high-fibre diet on bacterial populations in gastrointestinal tracts of obese- and lean genotype pigs. Appl Environ Microbiol 44, 107-112.

200. Abrams SA, Griffin IJ, Hawthorne KM, et al. (2007) Effect of prebiotic supplementation and calcium intake on body mass index. J Pediatr 151, 293-298.

201. Kadooka Y, Sato M, Imaizumi K, et al. (2010) Regulation of abdominal adiposity by probiotics (Lactobacillus gasseri SBT2055) in adults with obese tendencies in a randomized controlled trial. Eur J Clin Nutr 64, 636-643.

202. Cani PD, Neyrinck AM, Fava F, et al. (2007) Selective increases of bifidobacteria in gut microbiota improve highfat-diet-induced diabetes in mice through a mechanism associated with endotoxaemia. Diabetologia 50, 2374-2383.

203. An HM, Park SY, Lee DK, et al. (2011) Antiobesity and lipid-lowering effects of Bifidobacterium spp. in high fat diet-induced obese rats. Lipids Health Dis 10, 116.

204. Luoto R, Kalliomaki M, Laitinen K, et al. (2010) The impact of perinatal probiotic intervention on the development of overweight and obesity: follow-up study from birth to 10 years. Int J Obes (Lond) 34, 1531-1537.

205. Turnbaugh PJ, Baeckhed F, Fulton L, et al. (2008) Diet-induced obesity is linked to marked but reversible alterations in the mouse distal gut microbiome. Cell Host Microbe 3, 213-223.

206. Wall R, Ross RP, Shanahan F, et al. (2009) Metabolic activity of the enteric microbiota influences the fatty acid composition of murine and porcine liver and adipose tissues. Am J Clin Nutr 89, 1393-1401.

207. Nagao K, Inoue N, Wang YM, et al. (2005) Dietary conjugated linoleic acid alleviates nonalcoholic fatty liver disease in Zucker $(f a / f a)$ rats. J Nutr 135, 9-13.

208. Loguercio C, Federico A, Tuccillo C, et al. (2005) Beneficial effects of a probiotic VSL\#3 on parameters of liver dysfunction in chronic liver diseases. J Clin Gastroenterol 39, 540-543

209. Baillie RA, Takada R, Nakamura M, et al. (1999) Coordinate induction of peroxisomal acyl-CoA oxidase and UCP-3 by dietary fish oil: a mechanism for decreased body fat deposition. Prostaglandins Leukot Essent Fatty Acids 60, 351-356

210. Huber J, Loffler M, Bilban M, et al. (2007) Prevention of high-fat diet-induced adipose tissue remodeling in obese diabetic mice by $n-3$ polyunsaturated fatty acids. Int $J$ Obes 31, 1004-1013.

211. Kabir M, Skurnik G, Naour N, et al. (2007) Treatment for 2 mo with $n-3$ polyunsaturated fatty acids reduces adiposity and some atherogenic factors but does not improve insulin sensitivity in women with type 2 diabetes: a randomized controlled study. Am J Clin Nutr 86, 1670-1679.

212. Hill AM, Buckley JD, Murphy KJ, et al. (2007) Combining fish-oil supplements with regular aerobic exercise improves 
body composition and cardiovascular disease risk factors. Am J Clin Nutr 85, 1267-1274.

213. Kratz M, Callahan HS \& Yang PY (2009) Dietary n-3-polyunsaturated fatty acids and energy balance in overweight or moderately obese men and women: a randomized controlled trial. Nutr Metab 6, 24-31.

214. Nielsen S, Nielsen DS, Lauritzen L, et al. (2007) Impact of diet on the intestinal microbiota in 10-month-old infants. J Pediatr Gastroenterol Nutr 44, 613-618.

215. Bayerdorffer EH, Oertel N, Lehn G, et al. (1989) Topographic association between active gastritis and Campylobacter pylori colonisation. J Clin Pathol 42, 834-839.

216. Graham GY (1989) Campylobacter pylori and peptic ulcer disease. Gastroenterology 96, 615-625.

217. Kusters JG, van Vliet AHM \& Kuipers EJ (2006) Pathogenesis of Helicobacter pylori infection. Clin Microbiol Rev 19, 449-490.

218. Oozeer R, Goupil-Feuillerat N, Alpert CA, et al. (2002) Lactobacillus casei is able to survive and initiate protein synthesis during its transit in the digestive tract of human flora-associated mice. Appl Environ Microbiol $\mathbf{6 8}$, 3570-3574.

219. Gerard P, Beguet F, Lepercq P, et al. (2004) Gnotobiotic rats harboring human intestinal microbiota as a model for studying cholesterol-to-coprostanol conversion. FEMS Microbiol Ecol 47, 337-343.
220. Pang X, Hua X, Yang Q, et al. (2007) Inter-species transplantation of gut microbiota from human to pigs. ISME J 1, 156-162.

221. Che C, Pang X, Hua X, et al. (2009) Effects of human fecal flora on intestinal morphology and mucosal immunity in human flora-associated piglet. Scand J Immunol 69, $223-233$.

222. Shen J, Zhang B, Wei H, et al. (2010) Assessment of the modulating effects of fructo-oligosaccharides on fecal microbiota using human flora-associated piglets. Arch Microbiol 192, 959-968.

223. Groenen MAM, Archibald AL, Uenishi H, et al. (2012) Pig genomes provide insight into porcine demography and evolution. Nature 491, 393-398.

224. Anonymous (1997) Consensus meeting on cereals, fiber and colorectal and breast cancers. ECP Consensus Panel on Cereals and Cancer. Eur J Cancer Prev 6, 512-514.

225. Weisburger JH, Reddy BS, Rose DP, et al. (1993) Protective mechanisms of dietary fibers in nutritional carcinogenesis. Basic Life Sci 61, 45-63.

226. Velazquez OC, Seto RW, Bain AM, et al. (1997) Deoxycholate inhibits in vivo butyrate-mediated BrDU labeling of the colonic crypt. J Surg Res 69, 344-348.

227. Le Gall M, Serena A, Jørgensen H, et al. (2009) The role of whole wheat grain and wheat and rye ingredients on the digestion and fermentation processes in the gut - a model experiment with pigs. Br J Nutr 102, 1590-1600. 